\title{
Caracterización espacial de la pobreza energética en México. Un análisis a escala subnacional
}

\section{Spatial characterization of fuel poverty in Mexico. An analysis at the subnational scale}

\author{
Rigoberto García-OchoA* \\ Boris GRAIZBORD**
}

\begin{abstract}
This paper aims to apply the method for "Meeting of Absolute Energy Needs" to analyze energy poverty in Mexico at subnational scale. Results show that 36.7\% of Mexican households are energy poor, finding that "thermal comfort", "efficient refrigerator" and "gas or electric stove" are the economic goods with the highest deprivation levels. In addition, six groups of states with similar characteristics were found; a scenario that demonstrates the relevance of integrating the geographic dimension to the study of energy poverty. This paper proposes that energy poverty must be integrated as a key social dimension of energy sustainability policy in Mexico.
\end{abstract}

Keywords: human needs, deprivation, energy poverty, geography.

\section{Resumen}

En esta investigación se plantea como objetivo aplicar el método "Satisfacción de necesidades absolutas de energía” para analizar la pobreza energética en México a nivel subnacional. Los resultados muestran que 36,7\% de los hogares mexicanos viven en pobreza energética, encontrando que los bienes económicos "confort térmico", "refrigerador eficiente" y "estufa de gas o eléctrica" son los que presentan mayores niveles de privación. Se encontraron seis grupos de entidades federativas con características similares, escenario que evidencia la importancia de la dimensión geográfica en este tema. Se propone integrar la pobreza energética como una dimensión clave de la política nacional de sustentabilidad energética.

Palabras clave: necesidades humanas, privación, pobreza energética, geografía.

* El Colegio de la Frontera Norte, México. Correo-e: rigo@colef.mx

** El Colegio de México, México. Correo-e: graizbord@colmex.mx 


\section{Introducción}

La pobreza energética o pobreza de combustible ${ }^{1}$ emerge como tema de investigación en Europa desde principios de los ańos ochenta para abordar los problemas de salud relacionados con la falta de confort térmico en las viviendas. La primera crisis mundial del petróleo, en 1973, trajo como consecuencia un súbito incremento en el precio de los combustibles, principalmente el gas licuado y gas natural. Esta situación provocó que muchas familias no pudieran pagar la calefacción necesaria para mantener una temperatura de confort adecuada en sus viviendas, lo cual derivó en un incremento significativo de muertes y enfermedades respiratorias relacionadas con los climas invernales extremos.

Aunque la pobreza energética es una línea de investigación que se ha desarrollado principalmente en el Reino Unido e Irlanda, cabe destacar que empieza a tomar importancia en prácticamente toda Europa y, de manera emergente, en América Latina. Sin embargo, en este trabajo se destaca que, al considerar la dimensión espacial en el estudio de la pobreza energética, se advierte una serie de vacíos teóricos y metodológicos de los principales enfoques con los cuales se ha abordado esta línea de investigación en Europa.

Con este marco de referencia, el objetivo de este trabajo es ofrecer un primer acercamiento a la geografía de la pobreza energética en México. Se plantea que el conocimiento de las diferencias espaciales y regionales de la pobreza energética brinda elementos de análisis relevantes para integrar la relación entre energía y pobreza en la agenda de desarrollo nacional. Con el fin de alcanzar este objetivo, el trabajo se estructura en varias partes.

En la primera parte se describen brevemente, a manera de antecedentes, los supuestos de los enfoques de subsistencia y consensual, desde los cuales se ha abordado la pobreza energética en el Reino Unido e Irlanda, esto a través de la descripción de los principales trabajos de investigación que se han realizado en los últimos treinta años. De la misma manera, se describirá cómo la pobreza energética es un tema de investigación que está cobrando relevancia en la mayoría de los países europeos, así como en México y América Latina.

\footnotetext{
${ }^{1}$ Cabe aclarar que estos dos conceptos tienen el mismo significado. En el Reino Unido e Irlanda, lugares donde inicia y se consolida la pobreza energética como línea de investigación se usa el término pobreza de combustible, pero al expandirse esta línea de investigación a otros países europeos como Francia, Alemania, Italia y Polonia, así como en México y en general en América Latina, se empieza a utilizar el término pobreza energética en los principales trabajos de investigación. Si el lector desea profundizar en el estudio de esta aparente ambigüedad semántica, véase los trabajos de FinSH (2010) y Buzar (2007a; 2007b).
} 
En la segunda parte se explican, los supuestos teóricos y el marco metodológico de la propuesta desarrollada por García (2011 y 2014) para identificar y medir la pobreza energética en México, esto a través del método denominado "Satisfacción de necesidades absolutas de energía". Se explicará cómo este autor adopta dos ideas que se han discutido en el estudio de la pobreza para proponer el concepto "Necesidades absolutas de energía”. La primera tiene que ver con la conceptualización que Sen (1981) hace sobre privación absoluta y privación relativa y, la segunda, con la diferenciación propuesta por Max-Neef et al. (1991) entre necesidades, satisfactores y bienes económicos.

En la tercera parte se presentan los resultados obtenidos del cálculo del índice "Pobreza energética en el hogar", tanto a nivel nacional como estatal, ofreciendo un primer acercamiento a las diferencias espaciales y regionales encontradas, así como algunas de las implicaciones que la pobreza energética tiene en la agenda de desarrollo de México. Por último, se presentan las principales conclusiones y comentarios finales.

\section{Estudio de la literatura}

Como línea de investigación, la pobreza energética ha evolucionado en torno a los dos principales enfoques teóricos y metodológicos con los cuales se ha abordado el estudio de la pobreza: el enfoque de subsistencia (o biológico) y el enfoque consensual. Los trabajos pioneros en torno a la pobreza energética adaptaron el enfoque de subsistencia, según el cual "un hogar es pobre cuando sus ingresos no alcanzan a cubrir una serie de satisfactores básicos que son necesarios para mantener la eficiencia física de las personas" (Rowntree, 1901: 86). Con base en este enfoque, la pobreza energética se estima con un umbral del porcentaje de ingreso familiar dedicado a pagar la energía necesaria que se requiera en la vivienda, especialmente la energía necesaria para la calefacción (Lewis, 1982; Boardman, 1991 y 2010; Bradshaw, 2008).

Boardman (1991: 34) señala que la pobreza energética se debe principalmente a los bajos ingresos y el uso de equipos ineficientes, destacando así el papel que desempeña la eficiencia energética para reducir el consumo de energía en los hogares y, como consecuencia, la proporción del ingreso destinado a pagar esa energía. Con esta perspectiva propuso lo que es hasta hoy la definición más conocida de pobreza energética: "un hogar se encuentra en pobreza energética cuando no puede tener los servicios adecuados de energía con el $10 \%$ de sus ingresos". Los resultados de Boardman (2010) indican que en 2008 aproximadamente 19\% de los hogares en el Reino Unido vivían en pobreza energética. 
La propuesta de Boardman (1991) ha sido cuestionada por Whyley y Callender (1997), Clinch y Healy (1999 y 2001), Healy y Clinch (2002a y 2002b) y Healy (2004), argumentando que existe una serie de limitaciones teóricas y metodológicas en torno a ella. Estos cuestionamientos han dado pie a una nueva línea de investigación en el estudio de la pobreza energética denominada enfoque consensual que, en realidad, es una adaptación del enfoque de privación relativa en el estudio de la pobreza, línea de investigación desarrollada por el científico social, Peter Townsend.

De acuerdo a esta perspectiva, las condiciones de privación están relacionadas con lo que piensan o sienten las personas en función de la estructura social e institucional en un momento y tiempo determinados. Las personas sufren entonces de privación relativa cuando no satisfacen las necesidades que en su momento son consideradas básicas o indispensables de acuerdo a las costumbres y cultura de la sociedad (Townsend, 1962).

Con este enfoque, Healy (2004) desarrolló una metodología para medir la pobreza energética que se aplicó primero en Irlanda y después en varios países europeos (véase por ejemplo SEI, 2003; Harris, 2005; Tirado y Ürge-Vorsatz, 2010, Thomson y Snell, 2013; Buzar, 2007a y 2007b). El enfoque consensual de la pobreza energética propone un índice que pondera una serie de indicadores objetivos y cualitativos. Los indicadores objetivos miden las condiciones de equipamiento de la vivienda, mientras que los subjetivos estiman cualitativamente el sentimiento de privación de las personas acerca de su situación de pobreza energética. ${ }^{2}$

Bouzarovski et al. (2012) apuntan que si bien los enfoques de subsistencia y consensual se han desarrollado y aplicado principalmente en el Reino Unido e Irlanda, están tomando relevancia científica en prácticamente todos los países de Europa. ${ }^{3}$ En este sentido se observa una tendencia similar en América Latina, como lo demuestra el trabajo de Kozulj (2009) quien analiza en 20 países de la región de América Latina y el

\footnotetext{
${ }^{2}$ Un problema que se observa en esta metodología es que no define un criterio homogéneo para ponderar los indicadores, situación que deriva en resultados diferentes en función del peso que tenga cada indicador. Por ejemplo, Thomson y Snell (2013: 568) aplicaron esta metodología en la Unión Europea y presentan los resultados de cuatro escenarios correspondientes al 2007 (cuatro ponderaciones diferentes a los indicadores). En general Dinamarca es el país con menos pobreza energética (menos de $3 \%$ de sus hogares) mientras que Portugal $(\approx 20 \%)$, Chipre $(\approx 22 \%)$, Rumania $(\approx 24 \%)$ y Bulgaria $(\approx 31 \%)$ son los que presentan los peores resultados.

${ }^{3}$ Se destaca en este punto que la relación entre energía y pobreza es un tema relevante de política pública en Europa. La legislación del Reino Unido, por ejemplo, implementó en 2001 la Estrategia Nacional de Pobreza de Combustible que, en el caso específico de Inglaterra, tuvo como resultado establecer el objetivo de erradicar para 2016 la pobreza de combustible (House of Commons, 2010). De la misma forma, el Comité Económico y Social Europeo propuso en 2011 que el tema de pobreza debe incorporarse como eje central en toda política. energética de la Unión Europea.
} 
Caribe cómo los servicios energéticos resultan indispensables para alcanzar los Objetivos de Desarrollo del Milenio y reducir la pobreza mundial. En el caso de México, el artículo 36 de la Ley General de Desarrollo Social (LGDS) establece que el Consejo Nacional de Evaluación de la Política de Desarrollo Social (Coneval) debe definir, identificar y medir la pobreza considerando con al menos ocho indicadores, uno de los cuales es "Acceso a los servicios básicos en la vivienda" que se compone a su vez por cuatro dimensiones: i) Acceso al agua, ii) Contar con drenaje, iii) Disposición de electricidad y iv) Servicio de combustible para cocinar. Se destaca entonces que, aunque no se define explícitamente un indicador de pobreza energética, la metodología propuesta por el Coneval considera que la privación social del acceso a la electricidad y el tipo de combustible para cocinar (gas o electricidad) es un elemento que contribuye a la pobreza en México.

La privación social de los servicios que brinda el uso de energía es retomada por García (2011 y 2014) para desarrollar el método "Satisfacción de necesidades absolutas de energía", en el cual se propone un índice multidimensional denominado "Pobreza energética en el hogar". Bajo este enfoque, la pobreza energética se ubica en el campo de los derechos sociales que son universales, interdependientes e indivisibles. Si una persona no satisface las necesidades humanas relacionadas con los usos de energía, no ejerce entonces sus derechos, lo cual implica una situación de pobreza.

Es así que el índice multidimensional de pobreza energética en el hogar implica la carencia de al menos uno de los servicios o bienes económicos que se consideran básicos para satisfacer necesidades humanas fundamentales: los cuales son: i) Iluminación, ii) Entretenimiento, iii) Calentamiento de agua, iv) Cocción de alimentos, $v$ ) Refrigeración de alimentos, y vi) Confort térmico en la vivienda.

Los resultados obtenidos en México en 2008 y 2010 muestran que aproximadamente $40 \%$ de los hogares viven en pobreza energética. Una de las conclusiones más importantes de estos trabajos es que se advierten diferencias regionales de la pobreza energética, ya que se analizaron también cinco entidades del país cuyos resultados fueron significativamente diferentes. ${ }^{4}$ García (2011) encontró que los principales factores explicativos de la pobreza energética son el nivel de ingreso, el tamańo de la localidad, el nivel de educación y el sexo del jefe del hogar, así como el tamańo de la vivienda. Tomando en cuenta las marcadas diferencias

\footnotetext{
${ }^{4}$ La fuente de información de estos trabajos es la Encuesta Nacional de Ingreso y Gasto de los Hogares correspondiente a 2008 y 2010, cuyos resultados son representativos a nivel nacional en los ámbitos urbano y rural. Sin embargo, en 2008 los resultados fueron también representativos en el Distrito Federal y los estados de Guanajuato, Jalisco, México, Querétaro, Sonora y Yucatán; mientras que en 2010 fueron representativos en el Distrito Federal y los estados de Chiapas, Guanajuato, México y Yucatán. Para mayor información véase Inegi (2009 y 2011).
} 
económicas y sociales que existen en el país, se plantea la relevancia de profundizar en el estudio de la pobreza energética en México incorporando la dimensión espacial. Se reconoce entonces que, aunque el espacio de análisis de la pobreza energética es el individuo o el hogar, ésta tiene una manifestación local y específica, por lo cual es necesario incorporar la dimensión territorial como un factor contextual de la misma.

\section{Método de satisfacción de necesidades absolutas de energía}

Con base en la revisión de literatura que se acaba de presentar, se propone aplicar el marco metodológico propuesto por García (2011 y 2014) para ofrecer una primera mirada a las diferencias espaciales y regionales de la pobreza energética en México.

\subsection{Concepción y definición de la pobreza energética}

Los supuestos teóricos de la metodología propuesta surgen del debate que en torno a la pobreza sostienen Sen (1981) y Peter Townsend (1979) sobre los conceptos de privación absoluta y privación relativa. Townsend afirma que toda propuesta por determinar con exactitud las necesidades sociales elimina de hecho el concepto de necesidad absoluta. Hay un relativismo total en un tiempo y espacio determinados ya que las necesidades cambian de acuerdo a las costumbres, cultura y crecimiento económico de las sociedades, así como el medio geográfico en que se desenvuelven. Esta idea representa, de hecho, la base teórica del enfoque consensual en el estudio de la pobreza que Healy (2004) adaptó a la pobreza energética.

Contrario a esta visión, Sen señala que Townsend falla en un punto crucial: no distingue las necesidades de los satisfactores. La idea central aquí es que lo que cambia de acuerdo al contexto histórico, social y cultural son los satisfactores, no las necesidades (Sen, 1981). De esta manera, la idea relativa complementa pero no sustituye la visión de la privación absoluta, ya que hay un núcleo irreductible de privación absoluta (necesidades) que existe antes de conocer el concepto relativo (satisfactores) que se tenga o perciba de la pobreza.

Para García (2014), las ideas de Sen sobre la complementariedad entre privación absoluta y relativa, así como la diferenciación entre necesidades y satisfactores son aportes relevantes que toma como base para conceptualizar la pobreza energética en los hogares. Señala que el punto clave es definir las necesidades y satisfactores en función de los usos de energía, pero sobre todo, se requiere determinar cómo la privación de estas necesidades implica vivir en pobreza energética. 
En este sentido, Max-Neefn et al. (1991: 40) señalan también que un error recurrente en la literatura sobre necesidades humanas es que no se hace explícita la diferencia entre necesidades y satisfactores, lo cual es un problema tanto epistemológico como metodológico cuando se aborda el tema de pobreza. Estos autores argumentan que cualquier necesidad fundamental que no es cubierta a plenitud revela un determinado nivel de pobreza. Así, desagregan las necesidades en dos categorías posibles: existenciales y axiológicas. Las primeras tienen que ver con el ser, tener, hacer y estar, mientras que las segundas las identifican con necesidades de subsistencia, protección, afecto, entretenimiento, participación, ocio, creación, identidad y libertad. El principal postulado que plantean estos autores respecto a las necesidades humanas fundamentales es que son "finitas, pocas y clasificables" y, además, "son las mismas en todas las culturas y en todos los períodos históricos".

Los satisfactores, por su parte, expresan la forma, estilo o moda en que una determinada sociedad le da significado a sus necesidades, y no existe una "correspondencia biunívoca" entre ellos, es decir, los satisfactores pueden cubrir varias necesidades. Esta satisfacción de necesidades se logra a través de los bienes económicos, los cuales son equipos, objetos o artefactos que incrementan o reducen la eficiencia de los satisfactores, mismos que tienen que ver con la forma en que una sociedad expresa sus necesidades, mientras que los bienes económicos son el medio por el cual las personas potencian los satisfactores para cubrir sus necesidades, y "esto es lo que cambia a través del tiempo y de las culturas".5

Con base en los planteamientos de Sen (1981) y Max-Neef et al. (1991) respecto a las necesidades humanas, García (2014: 17) propone la siguiente definición de pobreza energética: "Un hogar se encuentra en pobreza energética cuando las personas que lo habitan no satisfacen las necesidades de energía absolutas, las cuales están relacionadas con una serie de satisfactores y bienes económicos que son considerados esenciales, en un lugar y tiempo determinados, de acuerdo a las convenciones sociales y culturales".

Los supuestos implícitos en esta definición se describen a continuación:

1. Las necesidades básicas o fundamentales relacionadas con los usos de energía son absolutas, pocas y diferenciadas, y son las mismas en todas las culturas y periodos históricos. Esto representa entonces el núcleo irreductible de privación absoluta relacionado con la pobreza energética.

\footnotetext{
${ }^{5}$ Para una mejor comprensión de este tema, véase la matriz de necesidades y satisfactores en Max-Neef et al. (1991: 58-59).
} 
2. La dimensión relativa que implica el sentimiento de privación de las necesidades de energía, por su parte, se manifiesta en los bienes económicos y satisfactores, ya que son éstos los que cambian de acuerdo a las costumbres y cultura de las sociedades.

\subsection{Metodología}

Establecidos los supuestos que identifican si un hogar está en pobreza energética, queda por solucionar el problema de medición. Así, el primer paso de esta metodología consiste en determinar las necesidades energéticas. Se propone para ello relacionar los usos finales de la energía con las necesidades humanas correspondientes. Para el caso específico de México y de acuerdo a estimaciones de la Secretaría de Energía (gráfica 1), los usos finales de energía más importantes en el sector residencial son: 1 . Calentamiento de agua; 2. Cocción de alimentos; 3. Refrigerador; 4. Iluminación; 5. Confort térmico (aire acondicionado) ${ }^{6}$ y 6 . Entretenimiento. Considerando las necesidades axiológicas propuestas por MaxNeef et al. (1991) se propone que las necesidades protección, subsistencia, entendimiento, ocio, creación y placer son las que están relacionadas con los usos y servicios de la energía cuya privación implica vivir en pobreza energética (gráfica 1).

Establecidas las necesidades humanas relacionadas con los usos de energía, el siguiente paso es determinar los bienes económicos que actualizan y potencian los satisfactores que cubren estas necesidades. Para este fin, uno de los supuestos principales de este método es que considera como bienes económicos los equipos relacionados con los usos finales de energía más importantes en los hogares. La fuente de información utilizada para el caso específico de México es el Módulo de Condiciones Socioeconómicas de la Encuesta Nacional de Ingreso y Gasto de los Hogares (ENIGH) correspondiente al 2012, cuyas principales características metodológicas se resumen en el cuadro $1 .^{7}$

\footnotetext{
${ }^{6}$ Para el caso específico de México no se considera la calefacción ya que, de acuerdo a un análisis exhaustivo de las zonas climáticas en México con base en la escala de Köppen, son muy pocas las localidades en México donde se considera indispensable contar con un calefactor. Cabe destacar que no se resta importancia a este uso final: sin embargo, el análisis descriptivo de la fuente de información utilizada en este trabajo arrojó que solamente 2,9\% de los hogares en México tienen calefactor, valor estadísticamente no significativo al considerar que los resultados de la fuente de información son válidos a nivel estatal y para dos tamaños de localidades ( 0 a 2,4999 y 2500 o mayores), es decir, no son representativos por zona climática.

${ }^{7}$ Un aspecto relevante del Módulo de Condiciones Socioeconómicas de la ENIGH es que fue desarrollado en conjunto por el Instituto Nacional de Estadística y Geografía (Inegi) y el Consejo Nacional de Evaluación de la Política de Desarrollo Social (Coneval) para la medición multidimensional de la pobreza. Su cobertura geográfica es a nivel nacional y por entidad federativa en los ámbitos urbano y rural. De esta manera, en este trabajo se utiliza esta fuente de información para analizar a mayor detalle las diferencias espaciales y regionales de la pobreza energética en México.
} 


\section{Gráfica 1}

\section{Participación de los principales usos finales en el consumo total de energía y su relación con necesidades humanas}

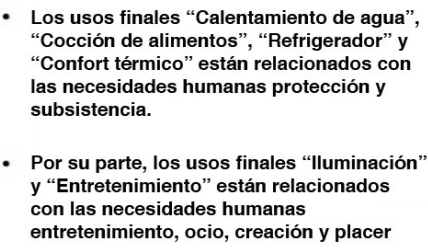

- Los usos finales "Calentamiento de agua", "Cocción de alimentos", "Refrigerador" y "Confort térmico" están relacionados con las necesidades humanas protección y subsistencia.

- Por su parte, los usos finales "lluminación" y "Entretenimiento" están relacionados con las necesidades humanas entretenimiento, ocio, creación y placer

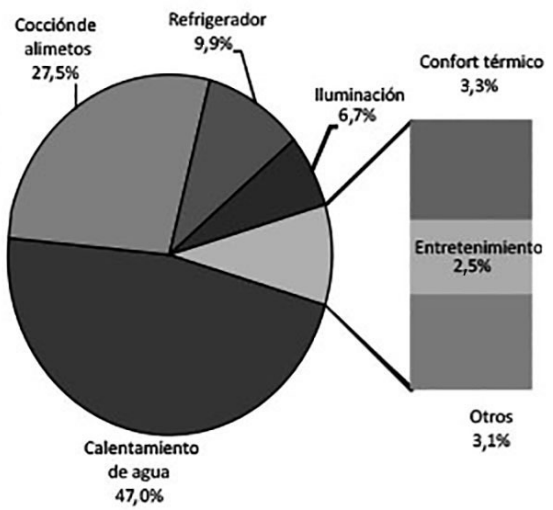

Fuente: Elaboración propia con información de Max-Neef et al. (1991: 58-59), Sener-AIE (2011: 94).

\section{Cuadro 1}

\section{Características principales del Módulo de Condiciones Socioeconómicas de la Encuesta Nacional de Ingreso y Gasto de los Hogares 2012}

\begin{tabular}{lcc}
\hline No. & Característica & \multicolumn{1}{c}{ Descripción } \\
\hline $1 \quad$ Objetivo & $\begin{array}{l}\text { Contar con datos sobre ingresos, salud, educación, seguridad } \\
\text { social, calidad y espacios de la vivienda, servicios básicos, } \\
\text { alimentación y redes sociales. }\end{array}$
\end{tabular}

2 Población objetivo Los hogares de nacionales o extranjeros que residen habitualmente en viviendas particulares dentro del territorio nacional.

3 Cobertura geográfica Nacional (urbano y rural).

4 Desglose geográfico Entidad federativa, localidades de 2500 y más habitantes y localidades menores de 2500 habitantes.

5 Tamaño de la muestra 68,505 viviendas.

6 Unidad de observación El hogar

7 Unidad de muestreo La vivienda

8 Unidad de análisis El hogar

9 Unidad de muestreo Marco Nacional de Viviendas 2002 del Inegi, construido a partir de la información demográfica y cartográfica que se obtuvo del XII Censo General de Población y Vivienda 2000.

10 Esquema de muestreo Probabilístico, bietápico, estratificado y por conglomerados.

11 Periodo de levanta- Del 27 de agosto al 21 de noviembre de 2012. miento 


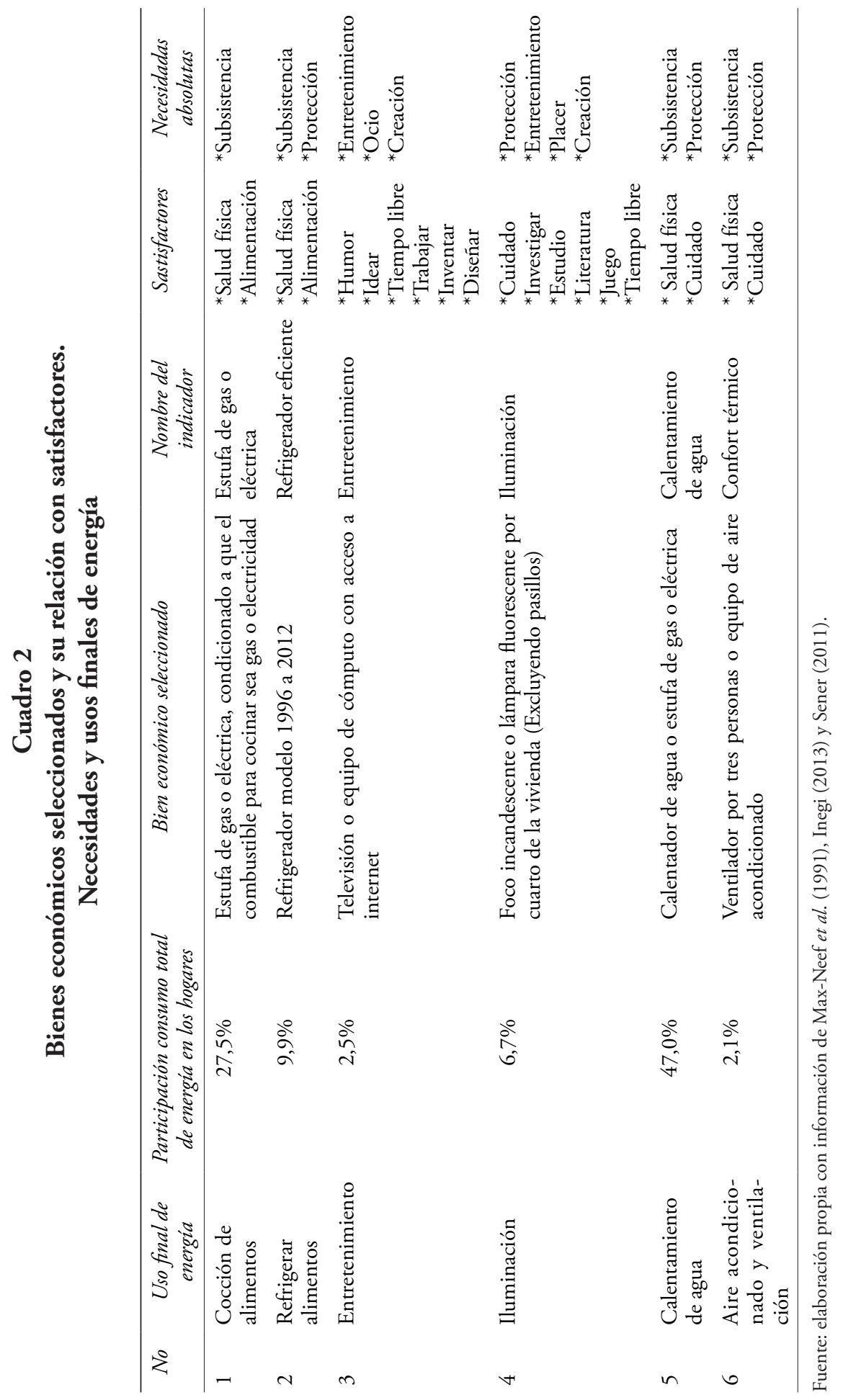


Para seleccionar los bienes económicos, que social y culturalmente se consideran necesarios, se realizó un análisis estadístico descriptivo de los 22 equipos considerados en la fuente de información de este trabajo. Se analizó comparativamente en cada equipo su participación en el consumo total de energía, el porcentaje de hogares que cuenta con cada equipo, así como el impacto social que significaría su privación.

Cabe señalar que este proceso de selección implica cierto grado de arbitrariedad ya que haría falta una contrastación empírica de los supuestos teóricos planteados. De acuerdo a una línea de investigación desarrollada por Lutzenhiser (1992, 1997), Wilhite et al. (1996), Lutzenhiser y Shove (1999) y Wilhite et al. (2000), las prácticas y acciones de los individuos en torno a los usos de la energía están permeadas por convenciones culturales que determinan un nivel de vida o estatus social. Esta perspectiva sustenta, en el fondo, la idea de una construcción social de la demanda de energía que se manifiesta en prácticas de consumo energético diferenciadas en función del significado social y cultural otorgado a dichas prácticas.

Si las prácticas de consumo de energía varían en función del contexto social y cultural, así como del nivel de vida o estatus de las personas y familias, se infiere entonces la posibilidad de un amplio espectro de opiniones y percepciones acerca del significado de privación o carencia. Esta situación plantea una serie de desafíos conceptuales y metodológicos para determinar los bienes económicos o servicios energéticos cuya privación implique pobreza energética.

De esta manera, un siguiente paso para fortalecer este enfoque es implementar algún método cualitativo (por ejemplo grupo focal o entrevista a profundidad) que identifique, con mejor precisión metodológica, los bienes que social y culturalmente se consideran necesarios. Sin embargo y, ante la imposibilidad de realizar por ahora una investigación de esta naturaleza en un país tan extenso y diverso como México, se destaca que la metodología propuesta representa un primer paso en esa dirección. Así, el cuadro 2 resume los bienes económicos y satisfactores seleccionados, así como su relación con las necesidades absolutas de energía previamente determinadas. ${ }^{8}$

Definidos los bienes económicos, los satisfactores y las necesidades absolutas de energía, el último paso de este método consiste en presentar una función de agregación o medición de la pobreza energética. De

\footnotetext{
${ }^{8}$ La explicación a detalle de los supuestos implícitos en la selección de estos bienes económicos (y discriminación de otros) escapa a los objetivos de este trabajo. Para un acercamiento a mayor detalle véase García (2011: 112-151).
} 
acuerdo con la conceptualización presentada, este método propone que un hogar vive en pobreza energética si:

$$
f\left(x_{i}\right)<1
$$

Siendo:

$$
f\left(x_{i}\right)=\frac{1}{n} \sum_{i=1}^{n} x_{i}
$$

En hogares localizados en climas templados donde la privación del bien económico "Confort térmico" no cubre ninguna necesidad, la expresión queda de la siguiente manera $(\mathrm{n}=5)$ :

$$
f\left(x_{i}\right)=\frac{X_{1}+X_{2}+X_{3}+X_{4}+X_{5}}{5}
$$

Donde: $\mathrm{X} 1=$ Iluminación, $\mathrm{X} 2=$ Entretenimiento, $\mathrm{X} 3=$ Calentamiento de agua, X4= Estufa de gas o eléctrica, X5= Refrigerador eficiente

Por otra parte, en hogares localizados en climas cálidos donde se considere esencial el bien "Confort térmico" para cubrir las necesidades humanas subsistencia y protección, la expresión queda de la siguiente manera $(\mathrm{n}=6)$ :

$$
f\left(x_{i}\right)=\frac{X_{1}+X_{2}+X_{3}+X_{4}+X_{5}+X_{6}}{6}
$$

Donde: $\mathrm{X} 1=$ Iluminación, $\mathrm{X} 2=$ Entretenimiento, $\mathrm{X} 3=$ Calentamiento de agua, X4= Estufa de gas o eléctrica, X5= Refrigerador eficiente y X6= Confort térmico.

Estas ecuaciones establecen que un hogar está en pobreza energética cuando no tiene la totalidad de los bienes económicos seleccionados (sólo de esta manera el resultado de la ecuación es menor a la unidad), es decir, cuando los miembros de un hogar sufren la carencia de al menos uno de estos bienes. El supuesto implícito en esta definición, identificación y medición de la pobreza energética en los hogares es que se otorga el mismo peso relativo a la carencia social de cada uno de los bienes económicos. Este umbral de privación social sigue entonces las bases conceptuales del enfoque multidimensional de la pobreza en México, en el cual se establece que ningún derecho humano es más importante que otro, por lo que el incumplimiento de un derecho afecta el cumplimiento de los demás el umbral de privación social (Coneval, 2009).

Antes de pasar a la sección de resultados, vale la pena detenerse un momento para explicar algunos problemas metodológicos relacionados con el bien denominado confort térmico, los cuales pueden derivar en 
algunas imprecisiones. En primer lugar, para determinar los hogares que requieren el confort térmico como un bien económico que ayuda a satisfacer necesidades humanas, se tomó como base la propuesta Howell et al. (2005) quienes determinan un umbral de temperatura máxima de $26^{\circ} \mathrm{C}$ para que operen los sistemas activos de ventilación, ${ }^{9}$ lo cual significa que todo hogar localizado en una zona climática cuya temperatura máxima promedio mensual supere $\operatorname{los} 26^{\circ} \mathrm{C}$ requiere que operen ventiladores (ASHRAE, 2013). Con este supuesto, se asignó el tipo de clima en cada uno de los municipios del país utilizando para ello la clasificación climática de Köppen presentada por García (1981), clasificación que se posicionó geográficamente en el mapa de climas del Inegi (mapa 1).

De esta manera, se encontró que los hogares que requieren el bien confort térmico son aquellos localizados en áreas donde se presentan siete tipos de climas: i) Cálido húmedo; ii) Cálido subhúmedo; iii) Semicálido; iv) Semicálido húmedo; v) Semicálido subhúmedo; vi) Cálido semiseco; vii) Cálido seco viii) Cálidos muy secos. ${ }^{10}$

Estos resultados evidencian que la mayoría de las entidades presentan en su totalidad climas muy cálidos en verano o cálidos todo el año (si necesitan el bien confort térmico), o bien, presentan climas templados (no requieren confort térmico), pero en los casos de Chiapas, Durango, Jalisco, Michoacán, Morelos, Oaxaca, San Luis Potosí y Zacatecas son entidades que se ubican en zonas climáticas templadas y cálidas. Como ya fue comentado, la fuente de información de este trabajo es el Módulo de Condiciones Socioeconómicas de la ENIGH 2012 (Inegi, 2013) cuyos resultados son válidos a nivel estatal y en los ámbitos urbano y rural, es decir, no son representativos a nivel municipal y mucho menos a nivel de zona climática, lo cual implica que los resultados obtenidos en las ocho entidades citadas no son representativos estadísticamente.

Para superar este problema metodológico se hizo un análisis estadístico descriptivo de los hogares encuestados (aplicando el factor de expansión correspondiente), cuyos resultados se muestran en el cuadro $3 .{ }^{11} \mathrm{La}$ solución propuesta se resume a continuación:

- Se observa que en Jalisco aproximadamente $89 \%$ de las viviendas se encuentran en climas templados, por lo cual se considera que la población de esta entidad no requiere el bien confort térmico.

${ }^{9}$ La publicación de estos autores corresponde a la Sociedad Americana de Ingenieros de Calefacción, Refrigeración y Aire Acondicionado (ASHRAE por sus siglas en inglés), asociación que marca los estándares de confort térmico más utilizados en el mundo.

${ }^{10}$ Es decir, todos los climas templados y fríos que se muestran en el cuadro 3 quedan fuera de esta clasificación.

${ }^{11}$ Véase el cuadro A.1 del anexo estadístico donde se muestra la frecuencia de viviendas encuestadas en los municipios de estas ocho entidades. Se agrega la clave estatal, clave municipal, tipo de clima y asignación del nivel de confort térmico. 


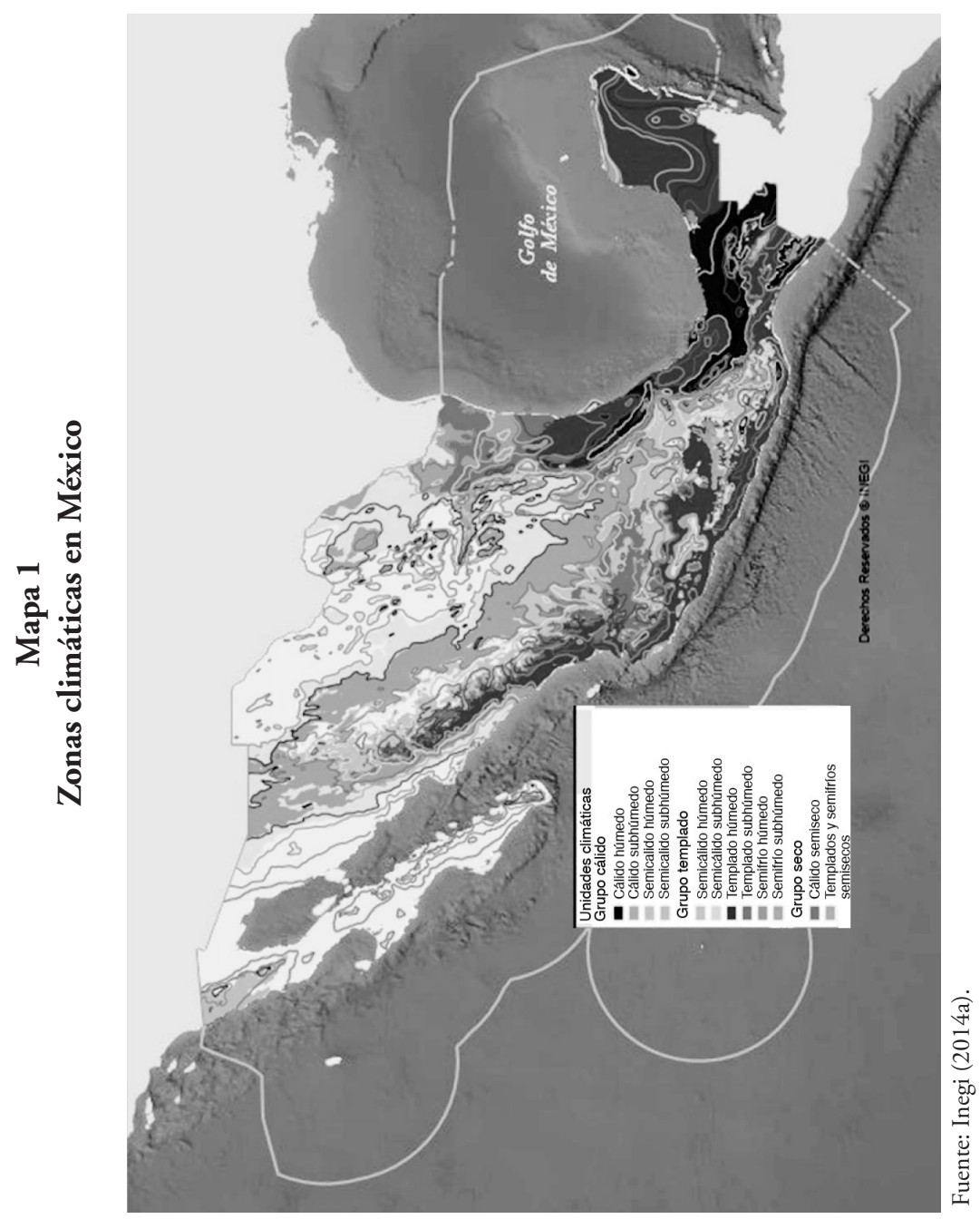




\section{Cuadro 3}

Distribución de los hogares en las entidades federativas con zonas climáticas cálidas y templadas

\begin{tabular}{lcccrr}
\hline \multicolumn{1}{c}{ Entidad } & $\begin{array}{c}\text { Hogares localizados en } \\
\text { climas cálidos }\end{array}$ & \multicolumn{2}{c}{$\begin{array}{c}\text { Hogares localizados en } \\
\text { climas templados }\end{array}$} & Total \\
& Cantidad & \multicolumn{1}{c}{$\%$} & Cantidad & \multicolumn{1}{c}{$\%$} \\
\hline Coahuila & 323,994 & 43,4 & 421,830 & 56,6 & 745,824 \\
Chiapas & 935,564 & 82,0 & 205,531 & 18,0 & $1,141,095$ \\
Durango & 177,004 & 41,3 & 251,576 & 58,7 & 428,580 \\
Jalisco & 213,705 & 11,3 & $1,684,862$ & 88,7 & $1,898,567$ \\
Michoacán & 159,352 & 19,0 & 679,343 & 81,0 & 838,695 \\
Morelos & 488,936 & 98,1 & 9364 & 1,9 & 498,300 \\
Oaxaca & 565,601 & 58,1 & 407,894 & 41,9 & 973,495 \\
San Luis Potosí & 309,846 & 46,4 & 357,529 & 53,6 & 667,375 \\
Zacatecas & 185,984 & 48,7 & 196,251 & 51,3 & 382,235 \\
\hline
\end{tabular}

Fuente: elaboración propia con base en datos de Inegi (2013) e Inegi (2014a).

- En Morelos 98\% de las viviendas se encuentran localizados en climas cálidos, resultado que sustenta la propuesta de que la población de esta entidad sí requiere el bien confort térmico.

- San Luis Potosí y Zacatecas presentan una relación aproximada a la unidad, es decir, que $50 \%$ de las viviendas requieren confort térmico y el otro $50 \%$ no lo requiere, mientras que en Coahuila, Durango y Oaxaca la relación porcentual es aproximadamente 60-40. Se establece entonces el supuesto de que existe una representatividad aproximada si se asigna a cada caso de la muestra de estas entidades la zona climática a la que pertenecen.

- Los casos de Chiapas y Michoacán presentan una relación porcentual aproximada de 80-20. Estos resultados evidencian, desde la perspectiva de este trabajo, que no existe una validez estadística para asignar a cada caso de la muestra la zona climática correspondiente. Ante este escenario, se decidió asignar a todos los casos la zona climática con mayor porcentaje, es decir, clima cálido para Chiapas, y templado para Michoacán.

En resumen, se advierte en términos generales una validez de los datos estadísticamente significativa en todas las entidades, con excepción de Chiapas y Michoacán. En el caso de Chiapas se puede sobreestimar la pobreza energética en una parte de $18 \%$ de las viviendas localizadas en climas templados; mientras que en Michoacán se puede subestimar en 
una parte de 19\% de viviendas localizadas en climas cálidos. Es pertinente aclarar que la única estrategia metodológica que puede minimizar el problema de representatividad de los datos sería realizar una encuesta representativa a nivel estatal y por zona climática, pero realizar un esfuerzo de esta naturaleza es imposible por el momento. Sin embargo, los diferentes instrumentos del Inegi, como la ENIGH y el MCS, son excelentes fuentes de información que permiten desarrollar estudios de esta naturaleza y, si bien nunca podrán ofrecer una representatividad total en todas las variables tomadas en cuenta, sí ofrecen una muy buena aproximación.

\section{Resultados}

\subsection{Pobreza energética en México}

Los resultados muestran que aproximadamente 11,093,000 hogares, los cuales representan $36,7 \%$ del total nacional, viven en pobreza energética en México (cuadro 4). El hecho de que una cantidad tan importante de hogares experimente la privación de al menos uno de los bienes económicos relacionados con los satisfactores y necesidades absolutas de energía representa un problema social relevante, debido a la asociación que tiene el uso de energía limpia y asequible para mejorar la calidad de vida y reducir la pobreza de la población. Sin embargo, es preciso destacar que se observan también diferencias significativas en la privación de los diferentes bienes económicos, lo cual indica que existen impactos diferenciados de cada uno de estos bienes sobre el índice general de pobreza energética. Los bienes económicos con mayor privación en los hogares son "Confort térmico" (33\%), ${ }^{12}$ "Refrigerador eficiente" $(21,1 \%)$ y "Estufa de gas o eléctrica" (16,6\%); mientras que "Calentamiento de agua" (8,7\%), "Entretenimiento" $(5,5 \%)$ e "Iluminación" $(2,2 \%)$ son los que presentan menor privación.

Un primer punto a tratar, en función de los resultados obtenidos, es cuestionar la visión reduccionista que tiene el enfoque multidimensional de la pobreza en México sobre el tema de energía en los hogares. De acuerdo al indicador de carencia por acceso a los servicios básicos en la vivienda del Coneval, hay aproximadamente 3,898,000 hogares en México que no cuentan con acceso a electricidad en sus viviendas o usan leña o carbón como combustible para cocinar. De acuerdo al método

\footnotetext{
${ }^{12}$ Como se mencionó en la sección de metodología, en el caso del bien económico "Confort térmico" se toman en cuenta exclusivamente los hogares localizados en las entidades que presentan climas cálidos y calurosos en la mayor parte de su territorio. De esta manera, los resultados muestran que 33\% de los 11,626,536 hogares en esta situación (no los 30,267,115 de total nacional) sufren la privación de este bien.
} 


\section{Cuadro 4}

Pobreza energética en el hogar y privación de bienes económicos (2012)

\begin{tabular}{llr}
\hline \multicolumn{1}{c}{ Concepto } & \multicolumn{1}{c}{ Hogares } & $\%$ \\
\hline Pobreza energética en el hogar & $11,092,947$ & 36,7 \\
Bienes económicos & & \\
Iluminación & 674,651 & 2,2 \\
Entretenimiento & $1,657,686$ & 5,5 \\
Calentamiento de agua & $2,625,363$ & 8,7 \\
Cocción de alimentos & $5,016,868$ & 16,6 \\
Refrigeración eficiente & $6,394,895$ & 21,1 \\
Confort térmico & $3,841,903$ & 33,0 \\
\hline
\end{tabular}

Fuente: elaboración propia como resultado de aplicar el Método de satisfacción de necesidades absolutas de energía en México.

Satisfacción de Necesidades Absolutas de Energía hay casi 11,093,000 hogares en situación de pobreza energética. Esto significa que hay aproximadamente 7,195,000 hogares en pobreza energética que el Coneval considera no sufren privación social por los servicios básicos de energía (figura 1).

Figura 1

Comparativo entre método de Satisfacción de Necesidades Absolutas de Energía y el Indicador de Carencia por Acceso a los Servicios Básicos en la Vivienda del Coneval

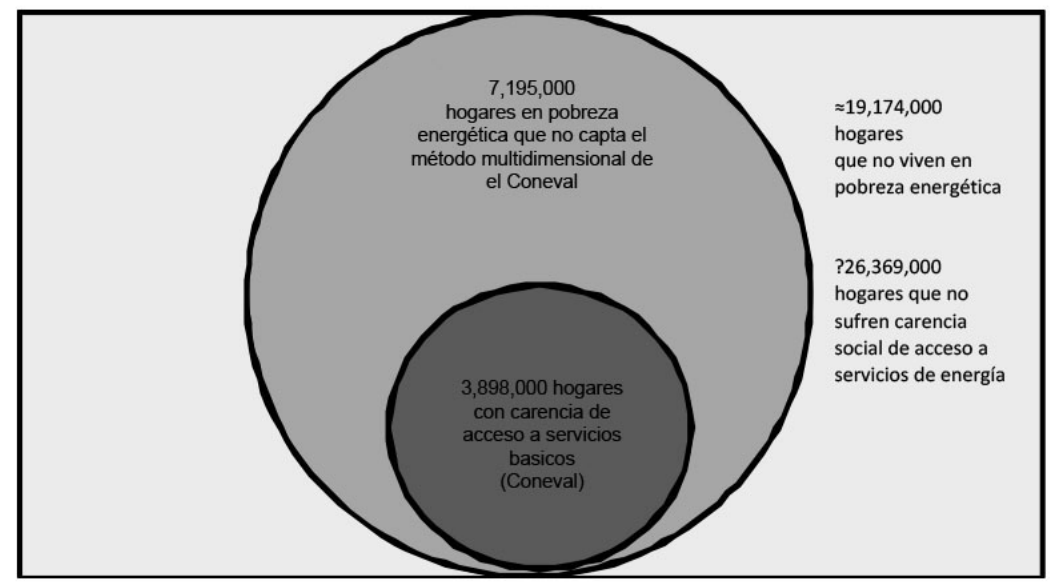

Fuente: elaboración propia con datos de Inegi (2013). 
Desde la perspectiva de este trabajo, los resultados obtenidos evidencian que la accesibilidad a energéticos de calidad es una condición necesaria que dista mucho de ser suficiente para que las personas cubran sus servicios básicos relacionados con el consumo de energía. La relación entre energía y pobreza demanda un enfoque integral que incorpore transversalmente los impactos económicos, sociales y ambientales del consumo de energía. Sólo de esta manera se puede producir un mejor conocimiento de cómo los usos de energía contribuyen a mejorar la calidad de vida y reducir la pobreza de la población.

\subsection{Diferencias espaciales de la pobreza energética}

En este trabajo se destaca que las profundas desigualdades económicas, sociales, culturales y geográficas que existen en México exigen una caracterización espacial de la privación de los diferentes bienes económicos para analizar a mayor profundidad la pobreza energética. En este sentido, a continuación se presenta un breve análisis a nivel estatal y, si bien es de esperarse una clara relación entre la privación de cada uno de estos bienes y el nivel de rezago social en cada entidad federativa, desde la perspectiva de este trabajo lo más importante es reconocer que los impactos sociales procedentes de la pobreza energética no responden necesariamente a esta relación.

Es necesario aclarar, antes de pasar a la caracterización territorial de la pobreza energética en México, que si bien el índice sintético propuesto en este trabajo resume en un solo valor el concepto de pobreza energética en los hogares, presenta dos debilidades metodológicas importantes. La primera, es que no ofrece información sobre el valor promedio de la disposición de los bienes económicos considerados, punto clave para conocer qué tan lejos están en promedio los hogares de cubrir las necesidades de energía, es decir, de pasar el umbral de pobreza energética en cada entidad. El segundo, es que oculta el peso de los diferentes componentes que lo conforman, tema de gran relevancia para conocer los impactos sociales procedentes de la pobreza energética ya que, como se verá más adelante, estos impactos son diferenciados, de ahí que resulte quizá más importante analizar los niveles de privación específicos de cada bien económico.

Reconociendo lo anterior, se propone entonces la siguiente caracterización regional (cuadro 5) $)^{13}$ en la cual aparece en primer plano el nivel

\footnotetext{
${ }^{13}$ La conformación de los seis grupos de entidades resultó de aplicar el análisis de conglomerados (clúster) jerárquico. Las variables empleadas fueron los seis bienes económicos (servicios de energía) que conforman el índice de Pobreza Energética en el Hogar.
} 


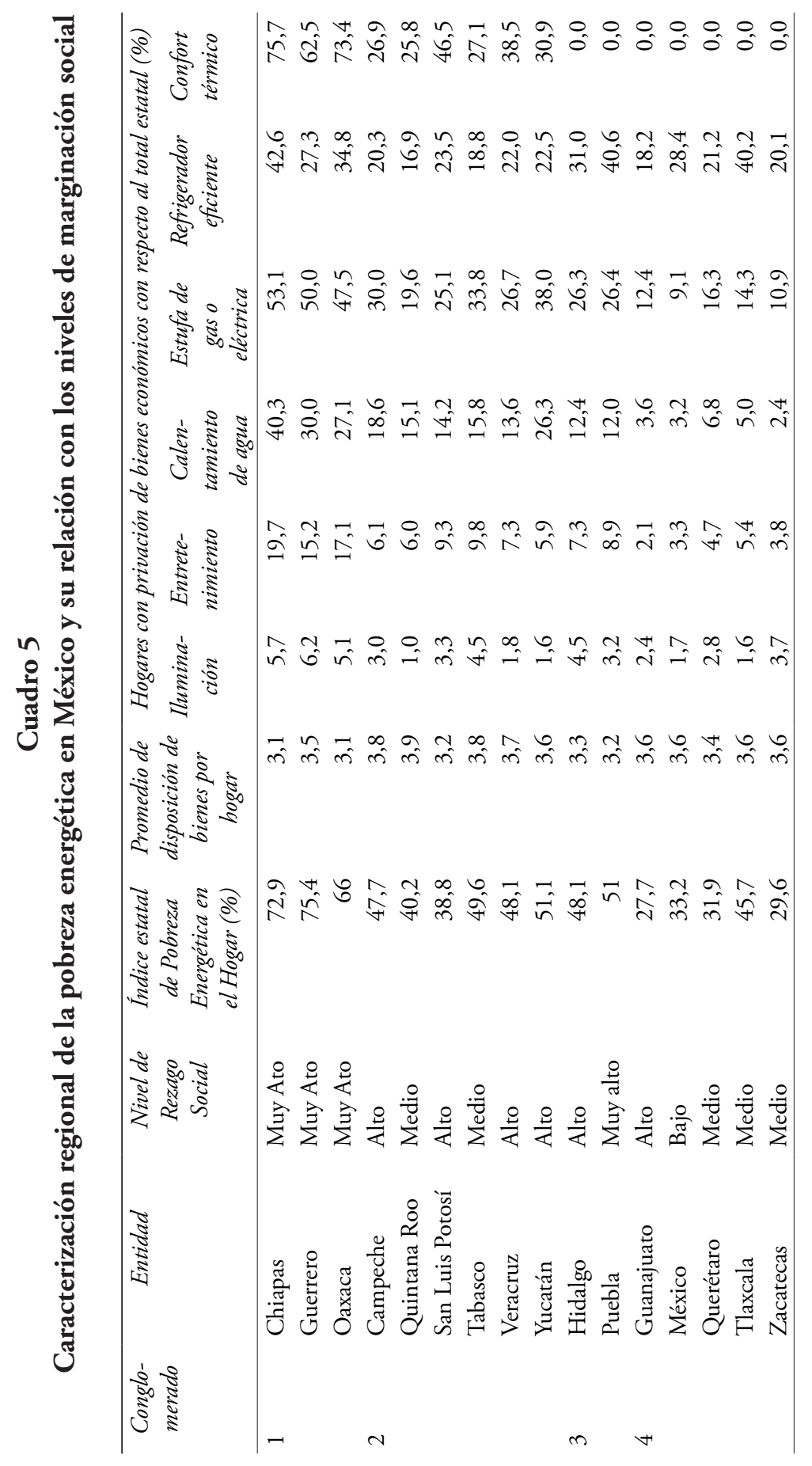




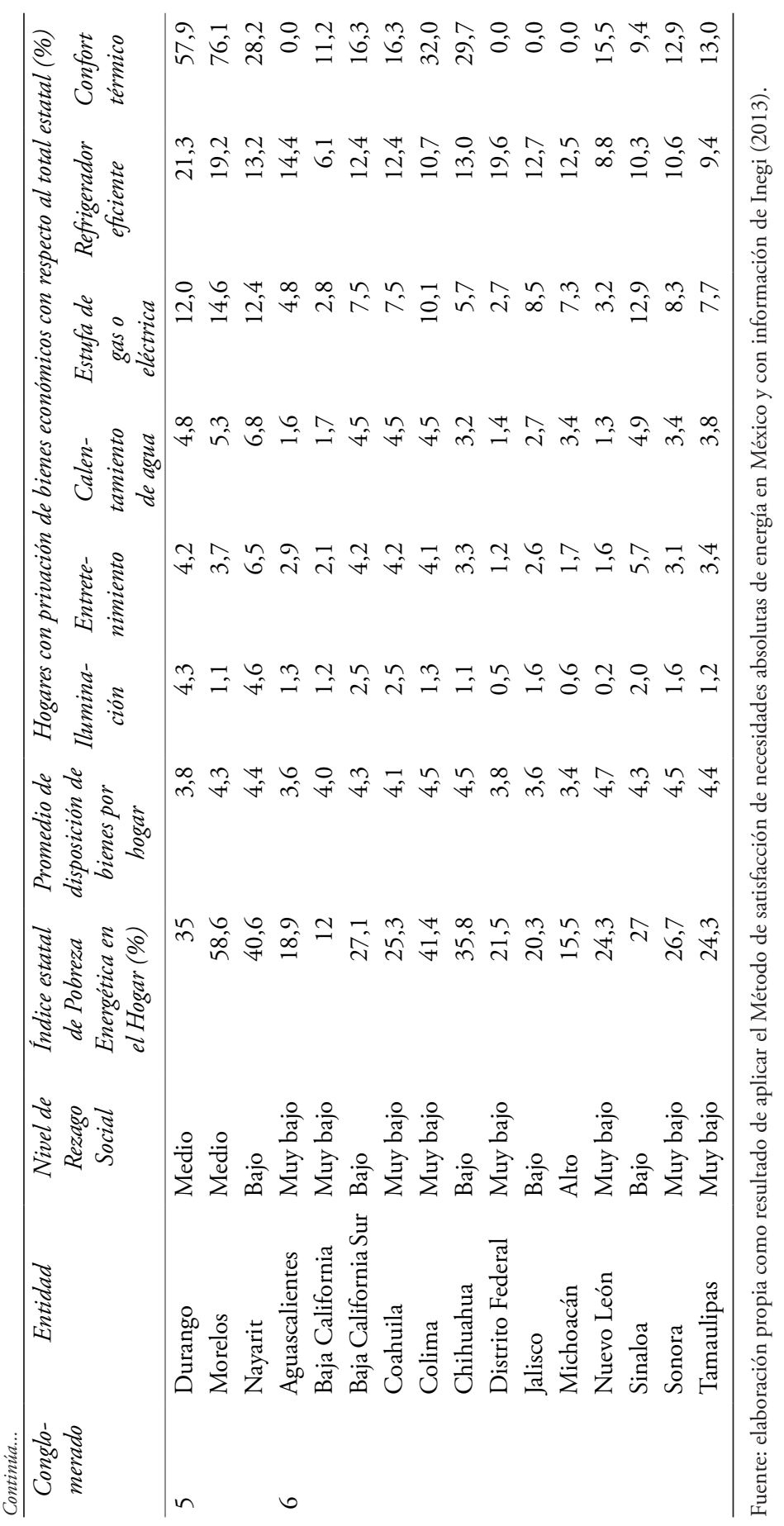


de rezago social, seguido del promedio de bienes económicos de los hogares, así como del porcentaje de hogares que sufren la privación de cada uno de los bienes que conforman el índice de pobreza energética en cada una de las entidades federativas del país.

En primer lugar se observa que Chiapas, Guerrero y Oaxaca (conglomerado 1), entidades con los índices de rezago social más altos, presentan también los niveles de privación promedio más altos, así como los promedios más bajos de disposición de los bienes económicos (3,1; 3,5 y 3,1, respectivamente); lo cual indica que para superar el umbral de pobreza energética necesitarían disponer de dos bienes económicos adicionales. Le sigue el grupo conformado por Campeche, Quintana Roo, San Luis Potosí, Tabasco, Veracruz y Yucatán (conglomerado 2), entidades que, sin bien no alcanzan los niveles observados en el grupo anterior, siguen presentando valores altos de privación de todos los bienes económicos y de rezago social y, además, sus niveles de disposición de bienes económicos permanecen bajos (varían entre 3,4 y 3,8). Estos resultados evidencian un patrón espacial en el sur del país que se caracteriza por presentar los mayores valores de pobreza energética (mapa 2).

Enseguida se encuentran dos grupos de entidades que presentan climas templados en la mayor parte de sus territorios y, como consecuencia, se considera que el bien económico "Confort térmico" no es indispensable para cubrir alguna necesidad humana. La característica principal de estos dos grupos es que, si bien se encuentran ubicados en el centro del país con climas templados similares, se observan diferencias con respecto a su asociación entre los niveles de privación de bienes económicos, su grado de marginación social; así como el promedio de disposición de bienes económicos. Hidalgo y Puebla (conglomerado 3), entidades con índices de rezago social alto y muy alto, respectivamente, conforman el primer grupo que se caracteriza por niveles significativos de privación de los bienes económicos "Refrigeración eficiente" y "Estufa de gas o eléctrica”.

Por su parte, Guanajuato, México, Querétaro, Tlaxcala y Zacatecas (conglomerado 4) presentan en promedio mejores índices de rezago social que las entidades anteriores ya que clasifican como medios y bajos (a excepción de Guanajuato que clasifica alto) y, en términos generales, la privación de todos los bienes económicos es significativamente menor. Se observa también que el promedio de disposición de bienes económicos varía muy poco entre ambos grupos de estados, 3,4 para Querétaro y 3,6 para Hidalgo, Estado de México, Tlaxcala y Zacatecas. Durango, Morelos y Nayarit (conglomerado 5) conforman un grupo de entidades que no corresponde a un patrón espacial específico. Estas entidades, con índices de rezago social medio y bajo, presentan en general valores intermedios de privación de bienes económicos, muy parecidos a los observados en el 


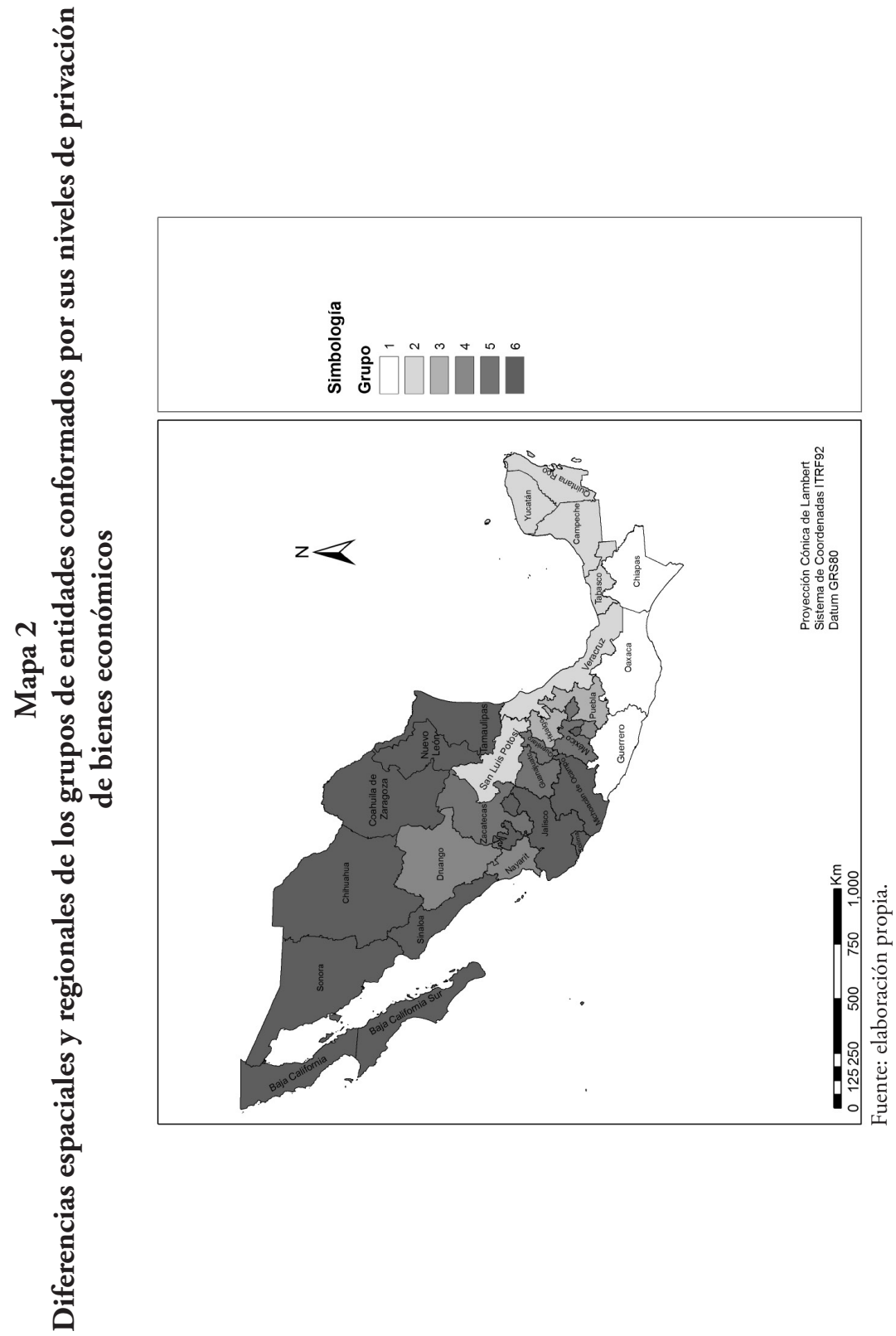


grupo anterior (Guanajuato, México, Querétaro, Tlaxcala y Zacatecas), con la particularidad de que el bien económico "Confort térmico" sí es necesario para cubrir necesidades humanas.

Los resultados muestran que un porcentaje elevado de hogares ubicados en estas tres entidades con climas cálidos, pero de manera espacial en Durango y Morelos, no cuentan con el bien económico "Confort térmico". Otro punto importante es que se observa un incremento en el promedio de disposición de bienes económicos, con valores entre 3,8 y 4,4 que son de los más altos observados, esto a pesar de que el promedio se calcula con seis bienes económicos, contrario al grupo de entidades con climas templados en los cuales se consideran cinco bienes.

El último grupo está conformado por Aguascalientes, Baja California, Baja California Sur, Coahuila, Colima, Chihuahua, Distrito Federal, Jalisco, Michoacán, Nuevo León, Sinaloa, Sonora y Tamaulipas (conglomerado 6), entidades que presentan, con excepción de Michoacán, niveles de rezago social bajos y muy bajos. Cabe mencionar que la mayoría de las entidades de este grupo, salvo Aguascalientes, Distrito Federal y Michoacán, alcanzan temperaturas extremas en verano, situación que explicaría el hecho de que si bien presentan los menores niveles de privación de todos los bienes económicos así como de los promedios de disposición de equipos, una parte importante de los hogares sufren la privación del bien "Confort térmico".

Se observa entonces un patrón regional en la frontera norte de México que, junto con las entidades Aguascalientes, Colima, el Distrito Federal y Michoacán presenta los niveles más bajos de pobreza energética en México. Reiterando lo comentado en el párrafo anterior, los promedios de disposición de bienes de este grupo de entidades es similar al del grupo anterior (conglomerado 5), a pesar de que los niveles de rezago social de estos últimos son mayores. En resumen, la geografía de la pobreza energética en México evidencia tres puntos principales:

a) Una asociación significativa entre los niveles de privación de los diferentes bienes económicos y el grado de rezago social de las entidades del país (con excepción de Michoacán). b) Una relación inversamente proporcional entre los niveles altos y muy altos de rezago social y promedio de disposición de bienes económicos; sin embargo, esta relación se diluye en los niveles medios, bajos y muy bajos de rezago social, como lo evidencian los resultados observados en los conglomerados 5 y 6 . Una hipótesis que podría plantearse ante este escenario es que la distancia al umbral de pobreza energética, expresada con el promedio de disposición de bienes, se reduce significativamente al superar los niveles medios de rezago social. c) En términos generales se observa un patrón constante que se caracteriza por una mayor privación de los bienes económicos 
relacionados con las necesidades absolutas subsistencia y protección, es decir, "Confort térmico", "Refrigerador eficiente", "Estufa de gas o eléctrica" y "Calentamiento de agua", y una menor privación de los bienes económicos relacionados con las necesidades absolutas entendimiento, ocio, creación y placer, que son los bienes "iluminación" y "entretenimiento". Sin embargo, este patrón constante de privación se expresa con diferente intensidad en el territorio nacional, escenario que brinda elementos de análisis relevantes para comprender cómo la pobreza energética impacta socialmente a la población.

Por otra parte, cabe destacar que la privación de los bienes económicos con mayor impacto sobre la pobreza energética en México, es decir, "Confort térmico", "Refrigerador Eficiente", "Estufa de gas o eléctrica" $y$, en menor medida "Calentamiento de agua", se asocia con problemas de salud que afectan a millones de personas en el mundo debido al incremento de la temperatura global por el cambio climático. El aumento en la morbilidad y mortalidad de golpes de calor, contaminación del aire interior en las viviendas y enfermedades diarreicas son los ejemplos más claros y visibles de estos impactos que perjudican principalmente a los grupos de población más vulnerables, que son los niños menores de cinco años y adultos mayores de 65 años (Patz, et al., 2005; McMichael et al., 2006; Costello et al., 2009; IPCC, 2012; WHO-WMO, 2012).

En el caso del bien económico "Confort térmico", el hecho de que casi 3,846,000 hogares (33\% del total de hogares ubicados en áreas con clima cálido) no cuenten al menos con un ventilador por cada tres personas que lo conforman, o bien, con equipo de aire acondicionado, es una condición que aumenta la probabilidad de enfermedades relacionadas con la aparición de eventos de calor extremo. Este tipo de enfermedades representa un problema de salud pública que cobrará mayor relevancia en el mediano y largo plazos por los impactos del cambio climático ya que, como lo señalan la Organización Mundial de la Salud y la Organización Meteorológica Mundial, hay una relación significativa entre el incremento en la temperatura y la mortalidad por golpe de calor. De hecho, se estima que por cada grado de incremento en la temperatura promedio global se producirá un incremento de dos a cinco por ciento en el número de muertes por olas de calor (WHO-WMO, 2012). Este tipo de impactos a la salud se presenta con mayor intensidad en personas mayores de 65 años que viven en ciudades debido al efecto "isla de calor urbano".

En este sentido, vale la pena comentar el estudio de McMichael, et al. (2003), quienes después de recabar información del número de muertes atribuidas a la presencia de olas de calor en distintas ciudades y países del 
mundo,${ }^{14}$ destacan que además de las condiciones económicas, grupo de edad y actitudes o conductas de la población, las condiciones de la vivienda, así como el uso de aire acondicionado y ventiladores, son los factores más importantes que afectan la vulnerabilidad de la población ante eventos de calor extremos.

Estos resultados sustentan la relevancia del bien económico "Confort térmico" para reducir la vulnerabilidad de la población ante eventos de calor extremos en México. Los bienes económicos "Refrigerador eficiente" y "Estufa de gas o eléctrica" presentan, por su parte, el segundo y tercer mayor nivel de privación en México, respectivamente. Aproximadamente $6,395,000$ hogares $(21,1 \%$ del total nacional) no cuentan con un refrigerador mínimamente eficiente y, cerca de 5,017,000 hogares (16,6\% del total nacional) usan leña o carbón como combustible para cocinar.

La privación de estos bienes económicos, además de que afectan la calidad de vida y confort de las personas, deriva en dos impactos relevantes de carácter social relacionados con el cambio climático. En primer lugar, el bien "Refrigerador eficiente" es un equipo indispensable para el tratamiento y conservación de los alimentos, acción necesaria de saneamiento ambiental para impedir, suprimir o reducir la transmisión de enfermedades diarreicas e infecciones intestinales.

Cabe señalar aquí que uno de los impactos más importantes del cambio climático sobre la salud de la población es, como lo señalan Checkley et al. (2000), Daniels y Mackinnon (2000), Tangkanakul y Tharmaphornpilas (2000), el incremento de enfermedades diarreicas agudas e infecciones intestinales. El aumento en la temperatura ambiente es un factor que propicia la reproducción de bacterias y parásitos en los alimentos por lo que, la privación del bien "Refrigerador eficiente", es un factor que puede contribuir a la ingesta de alimentos en mal estado y, como consecuencia, que las personas contraigan este tipo de enfermedades.

A nivel mundial, Fischer et al. (2013) estiman que en 2011 murieron alrededor de 700,000 personas por diarrea en el mundo. En el caso de México, aunque las muertes por diarrea y enfermedades infecciosas intestinales se han reducido significativamente en los últimos 14 años, todavía es una de las principales causas de muerte en los niños menores de cinco años y adultos de 65 años o más (Inegi, 2014b), son Chiapas, Oaxaca, Guanajuato, Veracruz, Puebla y Distrito Federal las entidades con mayor incidencia (Hernández et al., 2011). En cuanto a la "Estufa de gas o

${ }^{14}$ Estos autores encontraron que en Atenas murieron alrededor de 2000 personas por golpe de calor en el verano de 1987; 221 personas en Estados Unidos en 1994; 514 personas en Chicago en el verano de 1995; 619 personas en el Reino Unido en 1995; 2600 personas en la India en 1998 y un caso paradigmático documentado por estos autores son las 30,000 muertes ocurridas en agosto de 2003 en Europa, principalmente, en Francia. 
eléctrica”, los resultados advierten riesgos potenciales en la salud de las personas que no cuenten con este bien económico ya que, la combustión de leña o carbón, ocurre principalmente en el cuarto de cocina que se encuentra al interior de las viviendas, o bien, en lugares con poca ventilación. La exposición al humo que se produce con la quema de estos combustibles afecta principalmente a mujeres en edad fértil y menores de edad, sobre todo en áreas rurales de países pobres o en vías de desarrollo, produciendo efectos adversos en los embarazos como mortinatos y bajo peso al nacer (WHO-WMO, 2012).

Se estima que cada año mueren en los países en vías de desarrollo cerca de dos millones de personas, principalmente mujeres y nińos, por estar expuestos al humo que se produce por la quema de leña en la cocción de alimentos, situación que afecta principalmente a los países de ingresos medios y bajos (WHO, 2014). Éste es quizás el ejemplo más crudo que evidencia la relación entre energía y pobreza y, sobre todo, la importancia que adquiere el bien económico "Estufa de gas o eléctrica" para reducir los impactos adversos de la Pobreza energética en México. ${ }^{15}$

Se observa además que $8,7 \%$ de los hogares no cuentan con el bien "Calentamiento de agua". El uso de energía para calentamiento de agua es indispensable para muchas actividades de limpieza e higiene en el hogar como la ducha, la limpieza y desinfección de alimentos y utensilios. Una característica relevante asociada a este bien económico es que $47 \%$ del consumo total de energía en el sector residencial mexicano corresponde precisamente al calentamiento de agua, si es el uso final de energía más importante en dicho sector, lo cual tiene implicaciones directas en la economía familiar por el costo del combustible utilizado.

Además, el hecho de que 34\% del consumo final de energía en los hogares de México corresponda a la leña (Sener, 2012: 43) implica la posibilidad de impactos a la salud de las personas que usan este tipo de combustible para el calentamiento de agua; los cuales tienen que ver específicamente con la contaminación del aire al interior de la vivienda. Al tomar en cuenta que los efectos del cambio climático tendrán consecuencias sociales negativas, que de hecho ya se observan en la actualidad (Sarukhán et al., 2012), atender la pobreza energética puede ser una medida que tienda a reducir la vulnerabilidad social de la población en el corto, mediano y largo plazos. Aquí hay que mencionar que México es un país cuyos grupos de población más vulnerables (menores de cinco y mayores de 64 años) a los efectos del cambio climático representarán en

\footnotetext{
${ }^{15}$ Cabe recordar, tal y como se muestra en el cuadro 2 en la sección de metodología de este trabajo, que la privación social del bien económico "Estufa de gas o electricidad” implica también que el hogar correspondiente use leńa o carbón como combustible para cocinar.
} 
2030 poco más de $18 \%$ del total de la población, y cerca de $90 \%$ de la población vivirá en áreas urbanas al 2030 (Conapo, 2014).

Este escenario advierte sobre dos impactos sociales relevantes relacionados con la pobreza energética y el cambio climático. Por un lado, aumentará en las ciudades el número de personas y hogares vulnerables a los efectos de las olas de calor, así como a las enfermedades relacionadas con la contaminación del aire en las viviendas (por la quema de leña o carbón) y enfermedades intestinales. Por el otro, la distribución geográfica de la infraestructura de salud en México se caracteriza por una ineficiente concentración en algunos lugares y deja con limitada accesibilidad otros, lo que afecta a alrededor de 3,200,000 personas en poco más de 57,000 pequeñas localidades en diferentes regiones del país (Coneval, 2013).

De esta manera, la reducción de la pobreza energética y la vulnerabilidad social al cambio climático son dos temas asociados que requieren un enfoque integral para atender las necesidades de la población en los ámbitos urbano y rural. Por otra parte, contar con una iluminación mínimamente adecuada al interior de la vivienda es un requisito indispensable para realizar muchas de las actividades cotidianas cuando no se cuenta con iluminación natural. Así la privación del bien económico "Iluminación" aumenta la posibilidad de que las personas sufran enfermedades tales como trastornos visuales y cefalalgias, así como una serie de problemas ergonómicos al interior de las viviendas que pueden causar accidentes (Evans, 2001; Küller, et al. 2006; Tonello, 2008; Wall y Crosbie, 2009). Además, de acuerdo a la Sener-AIE (2011) la iluminación es el segundo uso final que demanda más electricidad en las viviendas de México, situación que afecta la economía de los hogares más pobres ya que tienen que destinar una proporción importante de su ingreso al pago de electricidad. Se observa entonces que la privación social del bien económico "Iluminación" afecta el confort de las personas y puede producir impactos en la salud que generalmente no son tomados en cuenta. Aunque sólo 2,2\% de los hogares mexicanos sufren la privación de este bien económico, hay que destacar que, al igual que otros bienes económicos asociados con consumos importantes de energía ("Calentamiento de agua", "Estufa de gas o eléctrica” y "Refrigerador eficiente"), el gasto energético para iluminar las viviendas afecta también el bienestar económico de los hogares, espacio que no cubre el método de Satisfacción de necesidades absolutas de energía, pero sí el enfoque multidimensional para medir la pobreza en México. 
Esto marca una clara diferenciación teórica y metodológica entre pobreza y pobreza energética que, ${ }^{16}$ desde la perspectiva de este trabajo, no consideran los enfoques tradicionales empleados en Europa para medir la pobreza energética. Respecto al bien económico "Entretenimiento", si bien está asociado con un uso final de energía que sólo demanda $2,5 \%$ del consumo total en los hogares, cabe destacar que representa uno de los rasgos más distintivos de la sociedad moderna. Mantenerse informado del entorno económico, social y cultural a nivel local, nacional o internacional; o bien, realizar actividades de ocio y esparcimiento, son actividades que en conjunto brindan a las personas la posibilidad de alcanzar un mejor nivel de vida en el sentido que les permite una mejor comunicación en el hogar, un espacio de relajamiento después de las actividades laborales cotidianas, así como tener acceso a información, cultura y conocimiento. Esta es una dimensión poco analizada en el tema de la pobreza energética pero que, desde la perspectiva de este trabajo, está vinculada con actividades de la vida cotidiana que proporcionan un desarrollo integral de las personas. Los resultados muestran que cerca de 1,658,000 hogares en México (5,5\% del total nacional), sufren la privación social de este bien económico.

\section{Conclusiones}

Los resultados obtenidos al aplicar el método de Satisfacción de necesidades absolutas de energía muestran que aproximadamente 37\% de los hogares mexicanos están en pobreza energética, con marcadas diferencias en los niveles de privación de cada uno de los bienes económicos. El análisis de la geografía de la pobreza energética evidencia que existen diferencias espaciales y regionales importantes, las cuales están vinculadas con los niveles de rezago social de la población. Se observa un patrón similar en cada uno de los grupos de entidades encontrados, pero con diferente intensidad.

En términos generales, hay una mayor privación social de los bienes económicos "Confort térmico", "Refrigerador eficiente", "Estufa de gas o eléctrica" y "Calentamiento de agua", los cuales satisfacen las necesidades absolutas Subsistencia y Protección, y una menor privación de los bienes económicos "Iluminación" y "Entretenimiento" que satisfacen las

${ }^{16}$ El concepto de Pobreza Energética en el Hogar y el método de Satisfacción de necesidades absolutas de energía aplicados en este trabajo consideran que pobreza energética significa la privación social de bienes económicos indispensables para satisfacer necesidades humanas fundamentales. De esta manera, la carencia de al menos uno de estos bienes es pobreza energética, mientras que no poder pagar el consumo de energía que demandan estos bienes, es pobreza. De hecho, la metodología de medición multidimensional de la pobreza del Coneval incluye el gasto de los hogares en los servicios básicos de la vivienda (entre estos, el gasto en energía) para determinar el umbral de bienestar económico (Coneval, 2009). 
necesidades absolutas entendimiento, ocio, creación y placer. Este escenario advierte sobre una problemática social relevante debido al papel que desempeña la energía para mejorar la calidad de vida y reducir la pobreza y los impactos a la salud de las personas.

Las profundas transformaciones urbanas y demográficas que experimentará el país en el corto y mediano plazos constituyen un marco de referencia para que la pobreza energética sea incorporada en la agenda de desarrollo nacional, principalmente en las políticas de cambio climático y combate a la pobreza. Se reconoce que esta propuesta presenta limitantes metodológicas.

La falta de información a nivel nacional y subnacional sobre el tipo, modelo e intensidad energética de los equipos o bienes económicos considerados, impide por el momento proponer indicadores más robustos que reflejen la adecuada satisfacción de necesidades humanas. El aporte de otras ciencias sociales como la sociología y antropología, por su parte, ayudaría a comprender cómo la construcción social de la demanda de energía determina los bienes económicos que la población considera indispensables.

Otra importante limitante metodológica es que, desde una perspectiva geográfica, el análisis del índice global de pobreza energética puede excluir a hogares que se encuentren en situación de pobreza energética en áreas (estado, ciudad, manzana, etc.) donde la mayoría de éstos no se encuentren en la misma situación. Este escenario advierte la necesidad de perfeccionar el método Satisfacción de necesidades absolutas de energía para que, además de identificar y medir la pobreza energética, se pueda cuantificar su intensidad mediante un tratamiento estadístico más riguroso, tanto en el índice global como en las diferentes dimensiones que lo componen. Esto significaría dar un paso relevante en este tema de investigación para estimar con mayor rigor metodológico sus impactos en localidad de vida de las personas. Al reconocer esta realidad hay que señalar también que el método de Satisfacción de necesidades absolutas de energía representa un primer esfuerzo para conceptualizar e identificar sistemáticamente la pobreza energética en México. El aporte de futuros trabajos será necesario para construir un marco teórico y metodológico más sólido en esta línea de investigación. 


\section{Anexo estadístico}

\section{Cuadro A1}

Frecuencia, tipo de clima y requerimiento de Confort térmico de los hogares, clasificados por entidad federativa y municipio*

\begin{tabular}{|c|c|c|c|c|c|c|}
\hline $\begin{array}{c}\text { Entidad } \\
\text { Federativa }\end{array}$ & $\begin{array}{c}\text { Clave } \\
\text { Entidad } \\
\text { Federativa }\end{array}$ & Municipio & $\begin{array}{c}\text { Clave } \\
\text { Municipal }\end{array}$ & $\begin{array}{l}\text { Frecuencia } \\
\text { (Viviendas) }\end{array}$ & Clima & $\begin{array}{c}\text { ¿Requiere } \\
\text { Confort } \\
\text { térmico? }\end{array}$ \\
\hline \multirow[t]{20}{*}{ Coahuila } & 05 & Acuña & 002 & 17,210 & Templado & No \\
\hline & 05 & Candela & 005 & 5434 & Cálido & Sí \\
\hline & 05 & Castaños & 006 & 5784 & Cálido & Sí \\
\hline & 05 & $\begin{array}{l}\text { Cuatro } \\
\text { Ciénegas }\end{array}$ & 07 & 10,240 & Cálido & Sí \\
\hline & 05 & $\begin{array}{l}\text { Francisco I. } \\
\text { Madero }\end{array}$ & 009 & 5933 & Cálido & Sí \\
\hline & 05 & Frontera & 010 & 30,144 & Cálido & Sí \\
\hline & 05 & Matamoros & 017 & 25,016 & Cálido & Sí \\
\hline & 05 & Monclova & 018 & 25,231 & Cálido & Sí \\
\hline & 05 & Múzquiz & 20 & 7009 & Cálido & Sí \\
\hline & 05 & Nadadores & 021 & 2940 & Cálido & Sí \\
\hline & 05 & Nava & 022 & 4352 & Templado & No \\
\hline & 05 & Parras & 024 & 15,245 & Cálido & Sí \\
\hline & 05 & $\begin{array}{l}\text { Piedras } \\
\text { Negras }\end{array}$ & 025 & 11,689 & Templado & No \\
\hline & 05 & $\begin{array}{l}\text { Ramos } \\
\text { Arizpe }\end{array}$ & 027 & 79,679 & Cálido & Sí \\
\hline & 05 & Sabinas & 028 & 7971 & Cálido & Sí \\
\hline & 05 & Saltillo & 030 & 400,268 & Templado & No \\
\hline & 05 & $\begin{array}{l}\text { San Juan } \\
\text { de Sabinas }\end{array}$ & 32 & 4268 & Cálido & Sí \\
\hline & 05 & Torreón & 035 & 79,441 & Cálido & Sí \\
\hline & 05 & Viesca & 36 & 15,099 & Cálido & Sí \\
\hline & 05 & Zaragoza & 038 & 4560 & Cálido & Sí \\
\hline \multirow[t]{10}{*}{ Chiapas } & 07 & Acala & 002 & 25,771 & Cálido & Sí \\
\hline & 07 & Arriaga & 009 & 11,370 & Cálido & Sí \\
\hline & 07 & Berriozábal & 012 & 11,424 & Cálido & Sí \\
\hline & 07 & Bochil & 013 & 7308 & Cálido & Sí \\
\hline & 07 & El Bosque & 014 & 18,270 & Templado & No \\
\hline & 07 & Coapilla & 018 & 16,016 & Cálido & Sí \\
\hline & 07 & $\begin{array}{l}\text { Comitán de } \\
\text { Domínguez }\end{array}$ & 019 & 54,827 & Templado & No \\
\hline & 07 & La Concordia & 020 & 16,680 & Cálido & Sí \\
\hline & 07 & Copainalá & 021 & 21,018 & Cálido & Sí \\
\hline & 07 & Chamula & 023 & 10,665 & Templado & No \\
\hline
\end{tabular}




\begin{tabular}{|c|c|c|c|c|c|c|}
\hline $\begin{array}{c}\text { Entidad } \\
\text { Federativa }\end{array}$ & $\begin{array}{c}\text { Clave } \\
\text { Entidad } \\
\text { Federativa }\end{array}$ & Municipio & $\begin{array}{c}\text { Clave } \\
\text { Municipal }\end{array}$ & $\begin{array}{l}\text { Frecuencia } \\
\text { (Viviendas) }\end{array}$ & Clima & $\begin{array}{c}\text { ¿Requiere } \\
\text { Confort } \\
\text { térmico? }\end{array}$ \\
\hline & 07 & Chenalhó & 026 & 16,796 & Templado & No \\
\hline & 07 & Chicomuselo & 030 & 38,045 & Templado & No \\
\hline & 07 & Huixtla & 040 & 11,940 & Cálido & Sí \\
\hline & 07 & $\begin{array}{l}\text { La Independen- } \\
\text { cia }\end{array}$ & 041 & 31,155 & Templado & No \\
\hline & 07 & Jiquilpas & 046 & 13,965 & Cálido & Sí \\
\hline & 07 & Jitotol & 047 & 22,574 & Cálido & Sí \\
\hline & 07 & Las Margaritas & 052 & 31,434 & Templado & No \\
\hline & 07 & Mitontic & 056 & 6741 & Templado & No \\
\hline & 07 & Motozintla & 057 & 10,959 & Cálido & Sí \\
\hline & 07 & Ocosingo & 059 & 39,202 & Cálido & Sí \\
\hline & 07 & $\begin{array}{l}\text { Ocozocoautla } \\
\text { de Espinosa }\end{array}$ & 061 & 15,718 & Cálido & Sí \\
\hline & 07 & Osumacinta & 063 & 11,480 & Cálido & Sí \\
\hline & 07 & Palenque & 065 & 13,770 & Cálido & Sí \\
\hline & 07 & Pichucalco & 068 & 20,195 & Cálido & Sí \\
\hline & 07 & Pijijiapan & 069 & 10,860 & Cálido & Sí \\
\hline & 07 & $\begin{array}{l}\text { Villa Comaltit- } \\
\text { lán }\end{array}$ & 071 & 23,245 & Cálido & Sí \\
\hline & 07 & Rayón & 073 & 17,130 & Cálido & Sí \\
\hline & 07 & Las Rosas & 075 & 18,550 & Templado & No \\
\hline & 07 & Salto de Agua & 077 & 12,880 & Cálido & Sí \\
\hline & 07 & $\begin{array}{l}\text { San Cristóbal } \\
\text { de las Casas }\end{array}$ & 078 & 24,327 & Templado & No \\
\hline & 07 & Sitalá & 082 & 18,900 & Cálido & Sí \\
\hline & 07 & Socoltenango & 083 & 13,676 & Cálido & Sí \\
\hline & 07 & Soyaló & 085 & 14,500 & Cálido & Sí \\
\hline & 07 & Suchiapa & 086 & 10,480 & Cálido & Sí \\
\hline & 07 & Suchiate & 087 & 14,098 & Cálido & Sí \\
\hline & 07 & Tapachula & 089 & 91,368 & Cálido & Sí \\
\hline & 07 & Tecpatán & 092 & 10,244 & Cálido & Sí \\
\hline & 07 & Tenejapa & 093 & 6720 & Templado & No \\
\hline & 07 & Teopisca & 094 & 13,356 & Templado & No \\
\hline & 07 & Tonalá & 097 & 23,178 & Cálido & Sí \\
\hline & 07 & La Trinitaria & 099 & 30,363 & Cálido & Sí \\
\hline & 07 & Tumbalá & 100 & 15,090 & Templado & No \\
\hline & 07 & $\begin{array}{l}\text { Tuxtla } \\
\text { Gutiérrez }\end{array}$ & 101 & 218,684 & Cálido & Sí \\
\hline & 07 & $\begin{array}{l}\text { Venustiano Ca- } \\
\text { rranza }\end{array}$ & 106 & 16,346 & Cálido & Sí \\
\hline & 07 & Villa Corzo & 107 & 14,980 & Templado & No \\
\hline & 07 & Villaflores & 108 & 30,321 & Cálido & Sí \\
\hline
\end{tabular}


Continúa...

\begin{tabular}{|c|c|c|c|c|c|c|}
\hline $\begin{array}{c}\text { Entidad } \\
\text { Federativa }\end{array}$ & $\begin{array}{c}\text { Clave } \\
\text { Entidad } \\
\text { Federativa }\end{array}$ & Municipio & $\begin{array}{c}\text { Clave } \\
\text { Municipal }\end{array}$ & $\begin{array}{l}\text { Frecuencia } \\
\text { (Viviendas) }\end{array}$ & Clima & $\begin{array}{c}\text { ¿Requiere } \\
\text { Confort } \\
\text { térmico? }\end{array}$ \\
\hline & 07 & Zinacantán & 111 & 14,476 & Templado & No \\
\hline \multirow[t]{21}{*}{ Durango } & 10 & Canatlán & 001 & 4470 & Cálido & Sí \\
\hline & 10 & Cuencamé & 004 & 18,778 & Templado & No \\
\hline & 10 & Durango & 005 & 219,997 & Cálido & Sí \\
\hline & 10 & Gómez Palacio & 007 & 23,223 & Templado & No \\
\hline & 10 & $\begin{array}{l}\text { Guadalupe } \\
\text { Victoria }\end{array}$ & 008 & 26,191 & Templado & No \\
\hline & 10 & Guanaceví & 009 & 2888 & Templado & No \\
\hline & 10 & Lerdo & 012 & 10,913 & Templado & No \\
\hline & 10 & Mapimí & 013 & 10,097 & Cálido & Sí \\
\hline & 10 & El Oro & 018 & 9569 & Cálido & Sí \\
\hline & 10 & $\begin{array}{l}\text { Pánuco de } \\
\text { Coronado }\end{array}$ & 020 & 2249 & Templado & No \\
\hline & 10 & Peñón Blnco & 021 & 8313 & Templado & No \\
\hline & 10 & Poanas & 022 & 5668 & Cálido & Sí \\
\hline & 10 & Pueblo Nuevo & 023 & 13,871 & Templado & No \\
\hline & 10 & $\begin{array}{l}\text { San Juan } \\
\text { de Guadalupe }\end{array}$ & 027 & 9879 & Templado & No \\
\hline & 10 & $\begin{array}{l}\text { San Juan del } \\
\text { Río }\end{array}$ & 28 & 10,190 & Templado & No \\
\hline & 10 & Santa Clara & 031 & 10,722 & Cálido & Sí \\
\hline & 10 & $\begin{array}{l}\text { Santiago } \\
\text { Papasquiaro }\end{array}$ & 032 & 8339 & Cálido & Sí \\
\hline & 10 & Súchil & 033 & 16,433 & Cálido & Sí \\
\hline & 10 & Tepehuanes & 035 & 3444 & Cálido & Sí \\
\hline & 10 & Tlahualilo & 036 & 7424 & Templado & No \\
\hline & 10 & Nuevo Ideal & 039 & 3042 & Cálido & Sí \\
\hline \multirow[t]{11}{*}{ Jalisco } & 14 & Ameca & 006 & 9585 & Cálido & Sí \\
\hline & 14 & $\begin{array}{l}\text { Atotonilco } \\
\text { el Alto }\end{array}$ & 013 & 15,204 & Cálido & Sí \\
\hline & 14 & $\begin{array}{l}\text { Autlán de } \\
\text { Navarro }\end{array}$ & 015 & 38,010 & Cálido & Sí \\
\hline & 14 & Ayotlán & 016 & 24,921 & Cálido & Sí \\
\hline & 14 & La Barca & 018 & 25,676 & Cálido & Sí \\
\hline & 14 & $\begin{array}{l}\text { Casimiro } \\
\text { Castillo }\end{array}$ & 021 & 33,138 & Templado & No \\
\hline & 14 & $\begin{array}{l}\text { Zapotlán } \\
\text { el Grande }\end{array}$ & 023 & 30,632 & Cálido & Sí \\
\hline & 14 & $\begin{array}{l}\text { Encarnación } \\
\text { de Díaz }\end{array}$ & 035 & 18,009 & Cálido & Sí \\
\hline & 14 & Etzatlán & 036 & 18,900 & Cálido & Sí \\
\hline & 14 & Guadalajara & 039 & 473,605 & Cálido & Sí \\
\hline & 14 & La Huerta & 043 & 31,958 & Templado & No \\
\hline
\end{tabular}




\begin{tabular}{|c|c|c|c|c|c|c|}
\hline $\begin{array}{c}\text { Entidad } \\
\text { Federativa }\end{array}$ & $\begin{array}{c}\text { Clave } \\
\text { Entidad } \\
\text { Federativa }\end{array}$ & Municipio & $\begin{array}{c}\text { Clave } \\
\text { Municipal }\end{array}$ & $\begin{array}{l}\text { Frecuencia } \\
\text { (Viviendas) }\end{array}$ & Clima & $\begin{array}{c}\text { ¿Requiere } \\
\text { Confort } \\
\text { térmico? }\end{array}$ \\
\hline & 14 & Jocotepec & 050 & 13,300 & Cálido & Sí \\
\hline & 14 & $\begin{array}{l}\text { Lagos de } \\
\text { Moreno }\end{array}$ & 053 & 18,603 & Cálido & Sí \\
\hline & 14 & Mascota & 058 & 23,900 & Cálido & Sí \\
\hline & 14 & Ocotlán & 063 & 46,263 & Cálido & Sí \\
\hline & 14 & $\begin{array}{l}\text { Ojuelos de } \\
\text { Jalisco }\end{array}$ & 064 & 20,160 & Cálido & Sí \\
\hline & 14 & Puerto Vallarta & 067 & 38,050 & Templado & No \\
\hline & 14 & $\begin{array}{l}\text { Villa } \\
\text { Purificación }\end{array}$ & 068 & 28,942 & Templado & No \\
\hline & 14 & Quitupan & 069 & 19,872 & Templado & No \\
\hline & 14 & El Salto & 070 & 51,124 & Cálido & Sí \\
\hline & 14 & $\begin{array}{l}\text { San Juan de } \\
\text { los Lagos }\end{array}$ & 073 & 26,143 & Cálido & Sí \\
\hline & 14 & $\begin{array}{l}\text { San Martín } \\
\text { Hidalgo }\end{array}$ & 077 & 40,052 & Cálido & Sí \\
\hline & 14 & $\begin{array}{l}\text { San Miguel } \\
\text { el Alto }\end{array}$ & 078 & 18,300 & Templado & No \\
\hline & 14 & Tala & 083 & 39,960 & Cálido & Sí \\
\hline & 14 & $\begin{array}{l}\text { Talpa de } \\
\text { Allende }\end{array}$ & 084 & 24,418 & Cálido & Sí \\
\hline & 14 & $\begin{array}{l}\text { Tamazula } \\
\text { de Gardiano }\end{array}$ & 085 & 51,226 & Cálido & Sí \\
\hline & 14 & Tenamaxtlán & 090 & 20,960 & Templado & No \\
\hline & 14 & Teocaltiche & 091 & 15,840 & Cálido & Sí \\
\hline & 14 & $\begin{array}{l}\text { Tepatitlán } \\
\text { de Morelos }\end{array}$ & 093 & 18,350 & Cálido & Sí \\
\hline & 14 & $\begin{array}{l}\text { Tlajomulco } \\
\text { de Zúñiga }\end{array}$ & 097 & 48,115 & Cálido & Sí \\
\hline & 14 & Tlaquepaque & 098 & 123,595 & Cálido & Sí \\
\hline & 14 & Tonalá & 101 & 93,780 & Cálido & Sí \\
\hline & 14 & Tuxpan & 108 & 22,485 & Templado & No \\
\hline & 14 & $\begin{array}{l}\text { Yahualica } \\
\text { de González } \\
\text { Gallo }\end{array}$ & 118 & 12,096 & Cálido & Sí \\
\hline & 14 & Zapopan & 120 & 349,069 & Cálido & Sí \\
\hline & 14 & Zapotiltic & 121 & 14,326 & Cálido & Sí \\
\hline Michoacán & & Angangueo & 005 & 7284 & Templado & No \\
\hline & 16 & Apatzingán & 006 & 34,956 & Cálido & Sí \\
\hline & 16 & Briseñas & 011 & 8658 & Templado & No \\
\hline & 16 & Buenavista & 012 & 24,353 & Cálido & Sí \\
\hline & 16 & Coeneo & 016 & 12,432 & Templado & No \\
\hline & 16 & Chilchota & 025 & 5886 & Templado & No \\
\hline
\end{tabular}


Continúa...

\begin{tabular}{|c|c|c|c|c|c|c|}
\hline $\begin{array}{l}\text { Entidad } \\
\text { Federativa }\end{array}$ & $\begin{array}{c}\text { Clave } \\
\text { Entidad } \\
\text { Federativa }\end{array}$ & Municipio & $\begin{array}{c}\text { Clave } \\
\text { Municipal }\end{array}$ & $\begin{array}{l}\text { Frecuencia } \\
\text { (Viviendas) }\end{array}$ & Clima & $\begin{array}{c}\text { ¿Requiere } \\
\text { Confort } \\
\text { térmico? }\end{array}$ \\
\hline & 16 & Gabriel Zamora & 033 & 29,237 & Cálido & Sí \\
\hline & 16 & Hidalgo & 034 & 14,960 & Templado & No \\
\hline & 16 & Huandacareo & 036 & 8590 & Templado & No \\
\hline & 16 & Huetamo & 038 & 32,577 & Cálido & Sí \\
\hline & 16 & Jacona & 043 & 14,040 & Templado & No \\
\hline & 16 & Jungapeo & 047 & 7800 & Templado & No \\
\hline & 16 & $\begin{array}{l}\text { Lázaro } \\
\text { Cárdenas }\end{array}$ & 052 & 25,931 & Cálido & Sí \\
\hline & 16 & Morelia & 053 & 330,222 & Templado & No \\
\hline & 16 & Múgica & 055 & 13,853 & Cálido & Sí \\
\hline & 16 & $\begin{array}{l}\text { Nuevo } \\
\text { Parangaricutiro }\end{array}$ & 058 & 5376 & Templado & No \\
\hline & 16 & Nuevo Urecho & 059 & 9444 & Cálido & Sí \\
\hline & 16 & Ocampo & 061 & 18,780 & Templado & No \\
\hline & 16 & Parácuaro & 064 & 9960 & Templado & No \\
\hline & 16 & Paracho & 065 & 1174 & Templado & No \\
\hline & 16 & Penjamillo & 067 & 2178 & Templado & No \\
\hline & 16 & La Piedad & 069 & 22,924 & Templado & No \\
\hline & 16 & Puruándiro & 071 & 10,810 & Templado & No \\
\hline & 16 & $\begin{array}{l}\text { Cojumatlán } \\
\text { de Régules }\end{array}$ & 074 & 5263 & Templado & No \\
\hline & 16 & Los Reyes & 075 & 18,039 & Templado & No \\
\hline & 16 & Sahuayo & 076 & 12,663 & Templado & No \\
\hline & 16 & Tacámbaro & 082 & 9855 & Templado & No \\
\hline & 16 & Tangancícuaro & 085 & 9240 & Templado & No \\
\hline & 16 & Tepalcatepec & 089 & 17,283 & Cálido & Sí \\
\hline & 16 & Tlalpujahua & 093 & 12,620 & Templado & No \\
\hline & 16 & Tuxpan & 098 & 15,250 & Templado & No \\
\hline & 16 & Tuzantla & 099 & 2580 & Cálido & Sí \\
\hline & 16 & Uruapan & 102 & 12,363 & Templado & No \\
\hline & 16 & Villamar & 104 & 6630 & Templado & No \\
\hline & 16 & Vista Hermosa & 105 & 10,140 & Templado & No \\
\hline & 16 & Zamora & 108 & 3485 & Templado & No \\
\hline & 16 & Zináparo & 109 & 6180 & Templado & No \\
\hline & 16 & Ziracuaretiro & 111 & 8806 & Templado & No \\
\hline & 16 & Zitácuaro & 112 & 36,873 & Templado & No \\
\hline \multirow[t]{6}{*}{ Morelos } & 17 & Amacúzac & 001 & 17,954 & Cálido & Sí \\
\hline & 17 & Atlatlahuacan & 002 & 18,449 & Cálido & Sí \\
\hline & 17 & Axochiapan & 003 & 7860 & Cálido & Sí \\
\hline & 17 & Ayala & 004 & 22,629 & Cálido & Sí \\
\hline & 17 & Coatlán del Río & 005 & 5850 & Cálido & Sí \\
\hline & 17 & Cuautla & 006 & 21,549 & Cálido & Sí \\
\hline
\end{tabular}




\begin{tabular}{|c|c|c|c|c|c|c|}
\hline $\begin{array}{c}\text { Entidad } \\
\text { Federativa }\end{array}$ & $\begin{array}{c}\text { Clave } \\
\text { Entidad } \\
\text { Federativa }\end{array}$ & Municipio & $\begin{array}{c}\text { Clave } \\
\text { Municipal }\end{array}$ & $\begin{array}{l}\text { Frecuencia } \\
\text { (Viviendas) }\end{array}$ & Clima & $\begin{array}{l}\text { ¿Requiere } \\
\text { Confort } \\
\text { térmico? }\end{array}$ \\
\hline & 17 & Cuernavaca & 007 & 103,596 & Cálido & Sí \\
\hline & 17 & $\begin{array}{l}\text { Emiliano } \\
\text { Zapata }\end{array}$ & 008 & 26,912 & Cálido & Sí \\
\hline & 17 & Jantetelco & 010 & 3080 & Cálido & Sí \\
\hline & 17 & Jiutepec & 011 & 83,013 & Cálido & Sí \\
\hline & 17 & Jojutla & 012 & 11,545 & Cálido & Sí \\
\hline & 17 & Mazatepec & 014 & 6048 & Cálido & Sí \\
\hline & 17 & Miacatlán & 015 & 24,268 & Cálido & Sí \\
\hline & 17 & Puente de Ixtla & 017 & 15,550 & Cálido & Sí \\
\hline & 17 & Temixco & 018 & 40,730 & Cálido & Sí \\
\hline & 17 & Tepalcingo & 019 & 3078 & Cálido & Sí \\
\hline & 17 & Tepoztlán & 020 & 1772 & Templado & No \\
\hline & 17 & $\begin{array}{l}\text { Tetela de } \\
\text { Volcán }\end{array}$ & 022 & 3840 & Templado & No \\
\hline & 17 & Tlaltizapán & 024 & 3726 & Cálido & Sí \\
\hline & 17 & Tlaquiltenango & 025 & 5856 & Cálido & Sí \\
\hline & 17 & Tlayacapan & 026 & 3752 & Templado & No \\
\hline & 17 & Xochitepec & 028 & 15,692 & Cálido & Sí \\
\hline & 17 & Yautepec & 029 & 33,489 & Cálido & Sí \\
\hline & 17 & Yecapixtla & 030 & 10,584 & Cálido & Sí \\
\hline & 17 & Zacatepec & 031 & 7478 & Cálido & Sí \\
\hline \multirow[t]{11}{*}{ Oaxaca } & 20 & $\begin{array}{l}\text { Asunción } \\
\text { Ixtltepec }\end{array}$ & 005 & 5502 & Templado & No \\
\hline & 20 & $\begin{array}{l}\text { El Barrio de } \\
\text { la Soledad }\end{array}$ & 010 & 10,150 & Cálido & Sí \\
\hline & 20 & $\begin{array}{l}\text { Ciénega de } \\
\text { Zimatlán }\end{array}$ & 013 & 4704 & Templado & No \\
\hline & 20 & Ciudad Ixtepec & 014 & 4382 & Cálido & Sí \\
\hline & 20 & $\begin{array}{l}\text { Cuilápam } \\
\text { de Guerrero }\end{array}$ & 023 & 16,320 & Templado & No \\
\hline & 20 & $\begin{array}{l}\text { Guevea } \\
\text { de Humboldt }\end{array}$ & 036 & 14,025 & Templado & No \\
\hline & 20 & $\begin{array}{l}\text { Heroica Ciudad } \\
\text { de Huajuapan } \\
\text { de León }\end{array}$ & 039 & 6566 & Templado & No \\
\hline & 20 & $\begin{array}{l}\text { Huautla de } \\
\text { Jiménez }\end{array}$ & 041 & 6929 & Templado & No \\
\hline & 20 & $\begin{array}{l}\text { Heroica Ciudad } \\
\text { de Juchitán de } \\
\text { Zaragoza }\end{array}$ & 043 & 18,855 & Cálido & Sí \\
\hline & 20 & Loma Bonita & 044 & 11,563 & Cálido & Sí \\
\hline & 20 & $\begin{array}{l}\text { Magdalena } \\
\text { Apasco }\end{array}$ & 045 & 14,056 & Templado & No \\
\hline
\end{tabular}


Continúa...

\begin{tabular}{|c|c|c|c|c|c|c|}
\hline $\begin{array}{c}\text { Entidad } \\
\text { Federativa }\end{array}$ & $\begin{array}{c}\text { Clave } \\
\text { Entidad } \\
\text { Federativa }\end{array}$ & Municipio & $\begin{array}{c}\text { Clave } \\
\text { Municipal }\end{array}$ & $\begin{array}{l}\text { Frecuencia } \\
\text { (Viviendas) }\end{array}$ & Clima & $\begin{array}{c}\text { ¿Requiere } \\
\text { Confort } \\
\text { térmico? }\end{array}$ \\
\hline & 20 & $\begin{array}{l}\text { Matías Rome- } \\
\text { roAvendańo }\end{array}$ & 057 & 5280 & Cálido & Sí \\
\hline & 20 & $\begin{array}{l}\text { Oaxaca de } \\
\text { Juárez }\end{array}$ & 059 & 24,684 & Templado & No \\
\hline & 20 & $\begin{array}{l}\text { Nejapa de } \\
\text { Madero }\end{array}$ & 064 & 11,232 & Cálido & Sí \\
\hline & 20 & $\begin{array}{l}\text { Oaxaca de } \\
\text { Juárez }\end{array}$ & 067 & 70,759 & Templado & No \\
\hline & 20 & $\begin{array}{l}\text { Ocotlán de } \\
\text { Morelos }\end{array}$ & 068 & 3536 & Templado & No \\
\hline & 20 & Salina Cruz & 079 & 17,712 & Cálido & Sí \\
\hline & 20 & $\begin{array}{l}\text { San Agustín } \\
\text { Yatareni }\end{array}$ & 087 & 6828 & Templado & No \\
\hline & 20 & $\begin{array}{l}\text { San Andrés } \\
\text { Huaxpaltepec }\end{array}$ & 090 & 7854 & Cálido & Sí \\
\hline & 20 & $\begin{array}{l}\text { San Andrés } \\
\text { Huayápam }\end{array}$ & 091 & 2688 & Templado & No \\
\hline & 20 & $\begin{array}{l}\text { San Antonio } \\
\text { de la Cal }\end{array}$ & 107 & 12,390 & Cálido & Sí \\
\hline & 20 & $\begin{array}{l}\text { San Dionisio } \\
\text { Ocotepec }\end{array}$ & 131 & 8310 & Cálido & Sí \\
\hline & 20 & $\begin{array}{l}\text { San Felipe } \\
\text { Jalapa de Díaz }\end{array}$ & 134 & 25,045 & Cálido & Sí \\
\hline & 20 & $\begin{array}{l}\text { San Francisco } \\
\text { Cahuacuá }\end{array}$ & 137 & 9150 & Templado & No \\
\hline & 20 & $\begin{array}{l}\text { San Francisco } \\
\text { Sola }\end{array}$ & 150 & 6510 & Templado & No \\
\hline & 20 & $\begin{array}{l}\text { San Ildefonso } \\
\text { Sola }\end{array}$ & 154 & 14,529 & Cálido & Sí \\
\hline & 20 & $\begin{array}{l}\text { San Jacinto } \\
\text { Amilpas }\end{array}$ & 157 & 5248 & Templado & No \\
\hline & 20 & Animas Trujano & 174 & 7305 & Cálido & Sí \\
\hline & 20 & $\begin{array}{l}\text { San Juan Bau- } \\
\text { tista Cuicatlán }\end{array}$ & 177 & 5138 & Cálido & Sí \\
\hline & 20 & $\begin{array}{l}\text { San Juan Bau- } \\
\text { tista Tuxtepec }\end{array}$ & 184 & 56,922 & Cálido & Sí \\
\hline & 20 & $\begin{array}{l}\text { San Juan } \\
\text { Colorado }\end{array}$ & 188 & 19,920 & Cálido & Sí \\
\hline & 20 & $\begin{array}{l}\text { San Juan } \\
\text { Cotzocón }\end{array}$ & 190 & 41,628 & Cálido & Sí \\
\hline & 20 & $\begin{array}{l}\text { San Juan } \\
\text { Guichicovi }\end{array}$ & 198 & 14,442 & Templado & No \\
\hline & 20 & San Juan Lalana & 205 & 12,990 & Templado & No \\
\hline
\end{tabular}


Continúa...

\begin{tabular}{|c|c|c|c|c|c|c|}
\hline $\begin{array}{c}\text { Entidad } \\
\text { Federativa }\end{array}$ & $\begin{array}{c}\text { Clave } \\
\text { Entidad } \\
\text { Federativa }\end{array}$ & Municipio & $\begin{array}{c}\text { Clave } \\
\text { Municipal }\end{array}$ & $\begin{array}{l}\text { Frecuencia } \\
\text { (Viviendas) }\end{array}$ & Clima & $\begin{array}{c}\text { ¿Requiere } \\
\text { Confort } \\
\text { térmico? }\end{array}$ \\
\hline & 20 & $\begin{array}{l}\text { San Melchor } \\
\text { Betaza }\end{array}$ & 257 & 6936 & Templado & No \\
\hline & 20 & $\begin{array}{l}\text { San Miguel } \\
\text { Amatitlán }\end{array}$ & 261 & 13,908 & Cálido & Sí \\
\hline & 20 & $\begin{array}{l}\text { Villa Sola } \\
\text { de Vega }\end{array}$ & 277 & 14,040 & Cálido & Sí \\
\hline & 20 & $\begin{array}{l}\text { San Miguel } \\
\text { Suchixtepec }\end{array}$ & 279 & 8250 & Templado & No \\
\hline & 20 & San Pablo Etla & 293 & 5700 & Templado & No \\
\hline & 20 & $\begin{array}{l}\text { San Pablo } \\
\text { Huixtepec }\end{array}$ & 295 & 6721 & Templado & No \\
\hline & 20 & $\begin{array}{l}\text { San Pedro } \\
\text { Amuzgos }\end{array}$ & 300 & 8835 & Cálido & Sí \\
\hline & 20 & $\begin{array}{l}\text { San Pedro } \\
\text { Comitancillo }\end{array}$ & 305 & 4930 & Cálido & Sí \\
\hline & 20 & $\begin{array}{l}\text { San Pedro } \\
\text { Humelula }\end{array}$ & 307 & 17,696 & Cálido & Sí \\
\hline & 20 & $\begin{array}{l}\text { San Pedro } \\
\text { Mixtepec-Dto. } \\
22-\end{array}$ & 318 & 14,005 & Cálido & Sí \\
\hline & 20 & $\begin{array}{l}\text { San Pedro } \\
\text { Pochutla }\end{array}$ & 324 & 5328 & Cálido & Sí \\
\hline & 20 & $\begin{array}{l}\text { Villa de Tutute- } \\
\text { pec de Melchor } \\
\text { de Ocampo }\end{array}$ & 334 & 23,940 & Cálido & Sí \\
\hline & 20 & $\begin{array}{l}\text { San Pedro y San } \\
\text { Pablo Tequixte- } \\
\text { pec }\end{array}$ & 340 & 7440 & Cálido & Sí \\
\hline & 20 & $\begin{array}{l}\text { San Sebastián } \\
\text { Tecomaxtlahua- } \\
\text { ca }\end{array}$ & 348 & 13,932 & Templado & No \\
\hline & 20 & $\begin{array}{l}\text { San Sebastián } \\
\text { Tutla }\end{array}$ & 350 & 9810 & Cálido & Sí \\
\hline & 20 & $\begin{array}{l}\text { Santa Catalina } \\
\text { Quieri }\end{array}$ & 361 & 14,022 & Cálido & Sí \\
\hline & 20 & $\begin{array}{l}\text { Santa Catarina } \\
\text { Juquila }\end{array}$ & 364 & 20,850 & Cálido & Sí \\
\hline & 20 & $\begin{array}{l}\text { Santa Cruz } \\
\text { Xoxocotlán }\end{array}$ & 385 & 16,522 & Templado & No \\
\hline & 20 & $\begin{array}{l}\text { Santa Cruz } \\
\text { Zenzontepec }\end{array}$ & 386 & 16,280 & Cálido & Sí \\
\hline & 20 & $\begin{array}{l}\text { Santa Lucía } \\
\text { del Camino }\end{array}$ & 390 & 29,893 & Templado & No \\
\hline
\end{tabular}


Continúa...

\begin{tabular}{|c|c|c|c|c|c|c|}
\hline $\begin{array}{c}\text { Entidad } \\
\text { Federativa }\end{array}$ & $\begin{array}{c}\text { Clave } \\
\text { Entidad } \\
\text { Federativa }\end{array}$ & Municipio & $\begin{array}{c}\text { Clave } \\
\text { Municipal }\end{array}$ & $\begin{array}{l}\text { Frecuencia } \\
\text { (Viviendas) }\end{array}$ & Clima & $\begin{array}{c}\text { ¿Requiere } \\
\text { Confort } \\
\text { térmico? }\end{array}$ \\
\hline & 20 & $\begin{array}{l}\text { Santa Lucía } \\
\text { Monteverde }\end{array}$ & 392 & 2660 & Templado & No \\
\hline & 20 & $\begin{array}{l}\text { Santa María } \\
\text { Atzompa }\end{array}$ & 399 & 13,535 & Cálido & Sí \\
\hline & 20 & $\begin{array}{l}\text { Santa María } \\
\text { Colotepec }\end{array}$ & 401 & 6048 & Cálido & Sí \\
\hline & 20 & $\begin{array}{l}\text { Santa María } \\
\text { Coyotepec }\end{array}$ & 403 & 15,724 & Cálido & Sí \\
\hline & 20 & $\begin{array}{l}\text { Santa María } \\
\text { del Tule }\end{array}$ & 409 & 3700 & Cálido & Sí \\
\hline & 20 & $\begin{array}{l}\text { Santa María } \\
\text { Huatulco }\end{array}$ & 413 & 6916 & Cálido & Sí \\
\hline & 20 & $\begin{array}{l}\text { Santa María } \\
\text { Jacatepec }\end{array}$ & 417 & 17,951 & Cálido & Sí \\
\hline & 20 & $\begin{array}{l}\text { Santa María } \\
\text { Petapa }\end{array}$ & 427 & 12,824 & Cálido & Sí \\
\hline & 20 & $\begin{array}{l}\text { Santa María } \\
\text { Zacatepec }\end{array}$ & 447 & 4690 & Cálido & Sí \\
\hline & 20 & $\begin{array}{l}\text { Santa María } \\
\text { Zaniza }\end{array}$ & 448 & 7696 & Templado & No \\
\hline & 20 & $\begin{array}{l}\text { Santiago } \\
\text { Apóstol }\end{array}$ & 452 & 6000 & Cálido & Sí \\
\hline & 20 & $\begin{array}{l}\text { Santiago } \\
\text { Jocotepec }\end{array}$ & 468 & 19,505 & Cálido & Sí \\
\hline & 20 & $\begin{array}{l}\text { Santiago } \\
\text { Juxtlahuaca }\end{array}$ & 469 & 3726 & Templado & No \\
\hline & 20 & $\begin{array}{l}\text { Santiago Pino- } \\
\text { tepa Nacional }\end{array}$ & 482 & 10,399 & Cálido & Sí \\
\hline & 20 & $\begin{array}{l}\text { Saniago } \\
\text { Tamazola }\end{array}$ & 484 & 11,532 & Cálido & Sí \\
\hline & 20 & $\begin{array}{l}\text { Santiago } \\
\text { Yosondúa }\end{array}$ & 500 & 11,509 & Cálido & Sí \\
\hline & 20 & $\begin{array}{l}\text { Santo Domingo } \\
\text { Tehuantepec }\end{array}$ & 515 & 10,150 & Cálido & Sí \\
\hline & 20 & $\begin{array}{l}\text { Teotitlán de } \\
\text { Flores Magón }\end{array}$ & 545 & 15,681 & Cálido & Sí \\
\hline & 20 & $\begin{array}{l}\text { Teotitlán } \\
\text { del Valle }\end{array}$ & 546 & 7412 & Templado & No \\
\hline & 20 & $\begin{array}{l}\text { Totontepec Vi- } \\
\text { lla de Morelos }\end{array}$ & 554 & 9162 & Templado & No \\
\hline & 20 & Unión Hidalgo & 557 & 6305 & Cálido & Sí \\
\hline & 20 & $\begin{array}{l}\text { Zimatlán de } \\
\text { Álvarez }\end{array}$ & 570 & 14,690 & Templado & No \\
\hline
\end{tabular}


Continúa...

\begin{tabular}{|c|c|c|c|c|c|c|}
\hline $\begin{array}{c}\text { Entidad } \\
\text { Federativa }\end{array}$ & $\begin{array}{c}\text { Clave } \\
\text { Entidad } \\
\text { Federativa }\end{array}$ & Municipio & $\begin{array}{c}\text { Clave } \\
\text { Municipal }\end{array}$ & $\begin{array}{l}\text { Frecuencia } \\
\text { (Viviendas) }\end{array}$ & Clima & $\begin{array}{c}\text { ¿Requiere } \\
\text { Confort } \\
\text { térmico? }\end{array}$ \\
\hline \multirow{32}{*}{$\begin{array}{l}\text { San Luis } \\
\text { Potosí }\end{array}$} & 24 & Aquismón & 003 & 10,788 & Templado & No \\
\hline & 24 & Cedral & 007 & 5798 & Templado & No \\
\hline & 24 & Cerritos & 008 & 7830 & Cálido & Sí \\
\hline & 24 & $\begin{array}{l}\text { Ciudad del } \\
\text { Maíz }\end{array}$ & 010 & 3420 & Cálido & Sí \\
\hline & 24 & $\begin{array}{l}\text { Ciudad } \\
\text { Fernández }\end{array}$ & 011 & 24,612 & Templado & No \\
\hline & 24 & Ciudad Valles & 013 & 28,401 & Templado & No \\
\hline & 24 & Charcas & 015 & 8441 & Templado & No \\
\hline & 24 & Ebano & 016 & 15,898 & Templado & No \\
\hline & 24 & Guadalcázar & 017 & 288 & Templado & No \\
\hline & 24 & Lagunillas & 019 & 9744 & Templado & No \\
\hline & 24 & Matehuala & 020 & 31,578 & Templado & No \\
\hline & 24 & $\begin{array}{l}\text { Mexquitic de } \\
\text { Carmona }\end{array}$ & 021 & 8204 & Templado & No \\
\hline & 24 & Moctezuma & 022 & 11,844 & Templado & No \\
\hline & 24 & Rioverde & 024 & 25,484 & Cálido & Sí \\
\hline & 24 & San Luis Potosí & 028 & 245,610 & Cálido & Sí \\
\hline & 24 & Santa Catarina & 031 & 8382 & Templado & No \\
\hline & 24 & $\begin{array}{l}\text { Santa María del } \\
\text { Río }\end{array}$ & 032 & 15,675 & Templado & No \\
\hline & 24 & $\begin{array}{l}\text { Soledad de Gra- } \\
\text { ciano Sánchez }\end{array}$ & 035 & 55,614 & Cálido & Sí \\
\hline & 24 & Tamasopo & 036 & 9264 & Templado & No \\
\hline & 24 & Tamazunchale & 037 & 19,571 & Cálido & Sí \\
\hline & 24 & Tampacán & 038 & 10,719 & Templado & No \\
\hline & 24 & Tamún & 040 & 10,017 & Templado & No \\
\hline & 24 & Tanlajás & 041 & 8960 & Templado & No \\
\hline & 24 & $\begin{array}{l}\text { Tanquián de } \\
\text { Escobedo }\end{array}$ & 042 & 4344 & Templado & No \\
\hline & 24 & Villa de Arriaga & 046 & 8715 & Templado & No \\
\hline & 24 & $\begin{array}{l}\text { Villa de Guada- } \\
\text { lupe }\end{array}$ & 047 & 9801 & Templado & No \\
\hline & 24 & Villa de la Paz & 048 & 3443 & Templado & No \\
\hline & 24 & Villa de Ramos & 049 & 11,571 & Templado & No \\
\hline & 24 & Villa de Reyes & 050 & 4407 & Templado & No \\
\hline & 24 & $\begin{array}{l}\text { Axtla de } \\
\text { Terrazas }\end{array}$ & 053 & 24,356 & Templado & No \\
\hline & 24 & Villa de Arista & 056 & 11,556 & Templado & No \\
\hline & 24 & El Naranjo & 058 & 5040 & Templado & No \\
\hline
\end{tabular}


Continúa...

\begin{tabular}{|c|c|c|c|c|c|c|}
\hline $\begin{array}{c}\text { Entidad } \\
\text { Federativa }\end{array}$ & $\begin{array}{c}\text { Clave } \\
\text { Entidad } \\
\text { Federativa }\end{array}$ & Municipio & $\begin{array}{c}\text { Clave } \\
\text { Municipal }\end{array}$ & $\begin{array}{l}\text { Frecuencia } \\
\text { (Viviendas) }\end{array}$ & Clima & $\begin{array}{l}\text { ¿Requiere } \\
\text { Confort } \\
\text { térmico? }\end{array}$ \\
\hline \multirow[t]{30}{*}{ Zacatecas } & 32 & Calera & 005 & 7644 & Templado & No \\
\hline & 32 & $\begin{array}{l}\text { Concepción } \\
\text { del Oro }\end{array}$ & 007 & 7280 & Templado & No \\
\hline & 32 & Fresnillo & 010 & 44,662 & Cálido & Sí \\
\hline & 32 & $\begin{array}{l}\text { General } \\
\text { Francisco R. } \\
\text { Murguía }\end{array}$ & 014 & 8338 & Templado & No \\
\hline & 32 & Guadalupe & 017 & 53,225 & Templado & No \\
\hline & 32 & Huanusco & 018 & 5022 & Cálido & Sí \\
\hline & 32 & Jalpa & 019 & 9842 & Templado & No \\
\hline & 32 & Juan Aldama & 022 & 2743 & Cálido & Sí \\
\hline & 32 & Juchipila & 023 & 7512 & Templado & No \\
\hline & 32 & Loreto & 024 & 14,147 & Cálido & Sí \\
\hline & 32 & Mazapil & 026 & 5510 & Templado & No \\
\hline & 32 & Miguel Auza & 029 & 10,140 & Templado & No \\
\hline & 32 & Morelos & 032 & 5278 & Cálido & Sí \\
\hline & 32 & Ojocaliente & 036 & 9010 & Cálido & Sí \\
\hline & 32 & Pánuco & 037 & 5382 & Cálido & Sí \\
\hline & 32 & Pinos & 038 & 9920 & Cálido & Sí \\
\hline & 32 & Río Grande & 039 & 22,902 & Templado & No \\
\hline & 32 & Sain Alto & 040 & 9884 & Cálido & Sí \\
\hline & 32 & Tabasco & 042 & 11,086 & Cálido & Sí \\
\hline & 32 & Tepechitlán & 045 & 3380 & Cálido & Sí \\
\hline & 32 & $\begin{array}{l}\text { Teúl de Gonzá- } \\
\text { lez Ortega }\end{array}$ & 047 & 2795 & Cálido & Sí \\
\hline & 32 & $\begin{array}{l}\text { Tlaltenango de } \\
\text { Sánchez Román }\end{array}$ & 048 & 7547 & Cálido & Sí \\
\hline & 32 & Valparaiso & 049 & 4632 & Cálido & Sí \\
\hline & 32 & Vetagrande & 050 & 5320 & Templado & No \\
\hline & 32 & Villa de Cos & 051 & 5434 & Cálido & Sí \\
\hline & 32 & Villa García & 052 & 6524 & Templado & No \\
\hline & 32 & Villa Hidalgo & 054 & 20,568 & Templado & No \\
\hline & 32 & Villa Nueva & 055 & 11,087 & Templado & No \\
\hline & 32 & Zacatecas & 056 & 55,329 & Cálido & Sí \\
\hline & 32 & Trancoso & 057 & 10,092 & Templado & No \\
\hline
\end{tabular}




\section{Fuentes consultadas}

ASHRAE (American Society of Heating Refrigerating and Air Conditioning Engineers) (2013), "Thermal environmental conditions for human occupancy”, ASHRAE, Atlanta, pp. 1-54.

Boardman, Brenda (2010), Fixing fuel poverty. Challenges and solutions, Earthscan, London.

Boardman, Brenda (1991), Fuel poverty: from cold homes to affordable warmth, Belhaven Press, London.

Bouzarovski, Stefan, Saska Petrova y Robert Sarlamanov (2012), "Energy poverty policies in the EU: A critical perspective", Energy Policy, núm. 49, Elsevier, pp. 76-82.

Bradshaw, Jonathan (2008), "Who is fuel poor?", Poverty, núm. 131, University of York, York, pp. 9-11.

Buzar, Stefan (2007a), Energy poverty in eastern Europe: hidden geographies of deprivation, Ashgate, Aldershot.

Buzar, Stefan (2007b), "When homes become prisons: The relational spaces of post socialist energy overty", Environment and Planning, 39 (8), Pion Ltd, London, pp. 1908-1925.

Checkley William, Leonardo Epstein, Robert Gilman, Dante Figueroa, Rosa Cama, Jonathan Patz y Robert Black (2000), "Effects of El Niño and ambient temperature on hospital admissions for diarrheal diseases in Peruvian children", The Lancet, núm. 355, Elsevier, $442-450$.

Clinch, Peter y Jonathan Healy (2001), "Cost-benefit analysis of domestic energy efficiency”, Energy Policy, núm. 29, Elsevier, pp. 113-124.

Clinch, Peter y Jonathan Healy (1999), "Housing standards and excess winter mortality in Ireland, (Environmental Studies Research Series-ESRS)", Working Paper 99/02, Department of Environmental Studies, University College, Dublin.

Conapo (Consejo Nacional de Población) (2014), "Estimaciones y proyecciones de la población”, Conapo, México. 
Coneval (Consejo Nacional de Evaluación de la Política de Desarrollo Social) (2013), "Medición de la pobreza en México y en las entidades federativas", <http://www.coneval.gob.mx/Medicion/ Paginas/Medici\%C3\%B3n/Pobreza\%202012/Resumen_ejecutivo.aspx>, 20 de mayo de 2014.

Coneval (Consejo Nacional de Evaluación de la Política de Desarrollo Social) (2009), "Metodología para la medición multidimensional de la pobreza en México", Coneval, México.

Costello Anthony, Mustafa Abbas, Adriana Allen, Sarah Ball, Richard Bellamy et al. (2009), "Managing the health effects of climate change", 373 (9676), Lancet y University College London Institute for Global Health Commission, London, pp.1693-1733.

Daniels, Nicholas y Linda Mackinnon (2000), "Vibrio parahaemolyticus infections in the United States, 1973-1998”, J Infect Dis, 181 (5), Oxford University Press, Oxford, pp. 1661-1666.

Evans, Gary (2001), "Environmental stress and health", en Andrew Baum, Tracey Revenson y Jerome Singer (eds.), Handbook of health psychology, Erlbaum, New Jersey, pp. 365-385.

FinSH (Financial and Support Instruments for Fuel Poverty in Social Housing) (2010), "Energy poverty: impact and public recognition in the United Kingdom, France, Germany, Italy and Poland", FinSH, Magdeburg.

Fischer, Christa, Igor Rudan, Li, Liu Harish, Nair Evropi, Theodoratou Zulfigar, Bhutta Katherine, O’Brien Harry, Campbell y Rober Black, (2013), "Global burden of childhood pneumonia and diarrhea”, The Lancet, 381 (9875), Elsevier, pp. 1405-1416.

García, Enriqueta (1981), Modificaciones al sistema de clasificación climática de Köppen, Editorial Larios, México.

García, Rigoberto (2014), Pobreza energética en América Latina, Serie Documentos de Proyecto Cepal, LC/W.576, Cepal-Naciones Unidas, Santiago de Chile, <http://www.cepal.org/cgi-bin/getProd.asp?.xml=/publicaciones/xml/8/52578/P52578.xml\&xsl=/ publicaciones/ficha.xsl\&base=/publicaciones/top_publicaciones . xsl>, 26 de abril de 2014 . 
García, Rigoberto (2011), "Pobreza energética y cambio climático. Una propuesta metodológica para el análisis de la relación entre energía, pobreza y cambio climático", tesis para obtener el grado de doctor, Centro de Estudios Demográficos, Urbanos y Ambientales de El Colegio de México, México.

Harris, Gwen (2005), Fuel poverty a local perspective: a study of fuel poverty among users of Finglas/Cabra, MABS, Dublin.

House of Commons (2010), Fuel poverty. Fifth report of session 2009-10, vol. I, Energy and Climate Change Committee, London.

Healy, Jonathan (2004), Fuel poverty and health: a pan european analysis, Ashgate Publishing Ltd., Aldershot.

Healy, Jonathan y John Clinch (2002a), "Fuel poverty, thermal comfort and occupancy: results of a national household-survey in Ireland", Applied Energy, 73 (3-4), Elsevier, pp. 329-343.

Healy, Jonathan y John Clinch, (2002b), "Fuel poverty in Europe: A cross-country analysis using a new composite measurement", (Environmental Studies Research Series, Working Papers), University College Dublin, Dublin, pp. 1-65.

Hernández, Cecilia, Guadalupe Aguilera y Graciela Castro (2011), "Situación de las enfermedades gastrointestinales en México", Enfermedades infecciosas y microbiología, 31 (4), Elsevier, pp. 137-151.

Howell, Ronald, Harry Sauer y William Coad, (2005), Principles of heating, ventilating and air conditioning: a textbook with design data based on the 2005 ASHRAE handbook Fundamentals, ASHRAE, Atlanta.

Inegi (Instituto Nacional de Estadística y Geografía] (2014a), Espacio y datos de México, Inegi, <http://www3.INEGI.org.mx/sistemas/ mapa/espacioydatos/>, 15 de julio de 2014.

Inegi (Instituto Nacional de Estadística y Geografía) (2014b), Estadísticas de mortalidad, Inegi, <http://www3.INEGI.org.mx/sistemas/ temas/default.aspx?s=est\&c=17484>, 20 de mayo de 2014 . 
Inegi (Instituto Nacional de Estadística y Geografía) (2013), Encuesta Nacional de Ingresos y Gastos de los Hogares 2012. Diseño muestral MCS 2012: formación de las Unidades Primarias de Muestreo para el levantamiento del MCS-2012: diseño de la muestra en base al Marco Nacional de Viviendas 2002 del Inegi, México, <http://www3.inegi.org.mx/sistemas/biblioteca/detalle. aspx?c=265\&s=inegi \&upc $=702825050573 \& \mathrm{pf}=$ prod $\& \mathrm{f}=2 \& \mathrm{cl}=$ 0\&tg=0>, 15 de julio de 2014 .

Inegi (Instituto Nacional de Estadística y Geografía) (2011), Encuesta Nacional de Ingresos y Gastos de los Hogares 2010, Inegi, <http:// www.inegi.org.mx/est/contenidos/Proyectos/Encuestas/Hogares/ regulares/Enigh/Enigh2012/ncv/default.aspx>, 11 de mayo de 2012.

Inegi (Instituto Nacional de Estadística y Geografía) (2009), Encuesta Nacional de Ingresos y Gastos de los Hogares 2008, Inegi, <http:// www.inegi.org.mx/est/contenidos/Proyectos/Encuestas/Hogares/ regulares/Enigh/Enigh2010/tradicional/default.aspx>, $30 \mathrm{de}$ mayo de 2010.

IPCC (Intergovernmental Panel on Climate Change) (2012), "Managing the risks of extreme events and disasters to advance climate change adaptation", special report of Working Groups I and II of the Intergovernmental Panel on Climate Change, Cambridge University Press, Cambridge y New York.

Kozulj, Roberto (2009), Contribución de los servicios energéticos a los Objetivos de Desarrollo del Milenio y a la mitigación de la pobreza en América Latina y el Caribe, Comisión Económica para América Latina y el Caribe (Cepal)-Sociedad Alemana de Cooperación Técnica (GTZ)-Programa de las Naciones Unidas para el Desarrollo (PNUD), Santiago de Chile.

Küller, Rikard, Seifeddin Ballal, Thorbjörn Laike, Byron Mikellides y Graciela Tonello (2006), "The impact of light and colour on psychological mood: a cross-cultural study of indoor work environments", Ergonomics, 49 (14), CRC Press, Londres, pp. 1496-1507.

Lewis, Paul (1982), Fuel poverty can be stopped, National Right to Fuel Campaign, Bradford. 
Lutzenhiser, Loren y Elizabeth Shove (1999), "Coordinated contractors and contracting knowledge: the organizational limits to interdisciplinary energy efficiency research and development in the U.S. and U.K.", Energy Policy, núm. 27, Elsevier, pp. 217-227.

Lutzenhiser, Loren (1997), "Social structure, culture and technology: modeling the driving forces of household consumption", en Paul Stem, Thomas Dietz, Vernon Ruttan, Robert Socolow y James Sweeney (eds.), Environmentally significant consumption: research directions, National Academy Press, Washington, pp. 77-91.

Lutzenhiser, Loren (1992), "A cultural model of household energy consumption”, Energy-The International Journal, 17 (1), Elsevier, pp. 47-60.

Max-Neef, Manfred, Antonio Elizalde, y Martín Hopenhayn (1991), Human scale development: conception, application and further reflections, The Apex Press, New York.

McMichael Anthony J., Rosalie Woodruff y Simon Hales (2006), "Climate change and human health: present and future risks", The Lancet, CCCLXVII (9513), Elsevier, London, pp. 859-869.

McMichael Anthony J., Diarmid Campbell-Lendrum, C.F. Corvalán, K.L. Ebi, A. Githeko, J.A. Scheraga y A. Woodward (eds.) (2003), Climate change and human health: risks and responses, World Health Organization, Geneva.

Patz, Jonathan, Diarmid Campbell-Lendrum, Tracey Holloway y Jonathan Foley (2005), "Impact of regional climate change on human health", Nature, núm. 438, Macmillan Publishers Limited, Londres, pp. 310-317.

Rowntree, Seebohm (1901), Poverty. The study of town fife, Macmillan, London.

Sarukhán, José, Julia Carabias, Patricia Koleff y Tania Urquiza-Haas (2012), Capital natural de México: acciones estratégicas para su valoración, preservación y recuperación, Comisión Nacional para el Conocimiento y Uso de la Biodiversidad, México. 
SEI (Sustainable Energy Ireland) (2003), A review of fuel poverty and low income housing, SEI, Dublin, <http://www.seai.ie/Grants/Warmer_Homes_Scheme/Fuel_Poverty_Report.pdf>, 26 de abril de 2014.

Sen, Amartya (1981), Poverty and famines. An essay on entitlement and deprivation, Clarendon Press, Oxford.

Sener (Secretaría de Energía) (2012), Balance Nacional de Energía 2011, Secretaría de Energía, México.

Sener-AIE (Secretaría de Energía-Agencia Internacional de Energía) (2011), Indicadores de sustentabilidad energética: 5 sectores, 5 retos, Sener, México.

Tangkanakul, Waraluk y Piyanit Tharmaphornpilas, D. Datapon, S. Sutantayawalee (2000), "Food poisoning outbreak from contaminated fish-balls", Journal of the Medical Association of Thailand = Chotmaihet thangphaet, 83 (11), Medical Association of Thailand, Bangkok, pp. 1289-1295.

Thomson, Harriet y Carolyn Snell (2013), "Quantifying the prevalence of fuel poverty across the European Union”, Energy Policy, núm. 52, Elsevier, pp. 563-572.

Tirado, Sergio, Diana Ürge-Vorsatz, (2010), Fuel poverty in Hungary. A first assessment, Report prepared for Védegylet-Protect the Future Society, Center for Climate Change and Sustainable Energy Policy, Budapest.

Tonello, Graciela (2008), "Seasonal affective disorder: lighting research and environmental psychology", Lighting Research and Technology, 40 (2), Sage Publications, pp. 103-110.

Townsend, Peter (1979), Poverty in the United Kingdom, Penguin, Harmoddsworth.

Townsend, Peter (1962), The last refuge, Routledge-Kegan Paul, London.

Wall, Ron y Crosbie Tracey (2009), "Potential for reducing electricity demand for lighting in households: An exploratory socio-technical study", Energy Policy, 37 (3), Elsevier, pp. 1021-1031. 
Wilhite, Harold, Elizabeth Shove, Loren Lutzenhiser, Willet Kemption (2000), After twenty years of "demand side management" (DSM) we know a little about individual behaviour but next to nothing about energy demand, IPCC Expert Meeting Conceptual Frameworks for Mitigation, Assessment from the Perspective of Social Science, Karlsruhe.

Wilhite, Harold, Hidetoshi Nakagami, Takashi Masuda, Yukiko Yamaga y Hiroshi Haneda (1996), "A cross-cultural analysis of household energy use behaviour in Japan and Norway", Energy Policy, 24 (9), Elsevier, pp. 795-803.

WHO (World Health Organization) (2014), Indoor air pollution from solid fuels and risk of low birth weight and stillbirth, <http:// apps.who.int/iris/bitstream/10665/43766/1/9789241505735_ eng.pdf>, 15 de junio de 2014.

WHO-WMO (World Health Organization-World Meteorological Organization) (2012), Atlas of health and climate, WHO y WMO, Geneva.

Whyley, Claire y Claire Callender (1997), Fuel poverty in Europe: evidence from the european household panel survey, Policy Studies Institute, London.

Recibido: 3 de septiembre de 2014. Corregido: 9 de enero de 2015. Aceptado: 13 de junio de 2015.

Rigoberto García-Ochoa. Doctor en estudios urbanos y ambientales por El Colegio de México, actualmente es profesor-investigador del Departamento de Estudios Urbanos y Medio Ambiente de El Colegio de la Frontera Norte en la sede regional de Nogales, Sonora. Sus líneas de investigación son pobreza energética y sustentabilidad urbana. Miembro del Sistema Nacional de Investigadores (candidato). Fue galardonado con el Premio Gustavo Cabrera Acevedo como mejor trabajo de investigación en Estudios Urbanos y Ambientales en 2011 y recibió una mención honorífica del Instituto Latinoamericano y del Caribe de Planificación Económica y Social (ILPES) y la Comisión Económica para América Latina y el Caribe (CEPAL) en el marco de las Primeras Jornadas de Planificación Económica y Social 2013. Entre sus últimas publicaciones 
destacan: "Pobreza energética en América Latina", documento de proyecto primeras jornadas de planificación, ILPES-CEPAL, Santiago de Chile, pp. 1-36 (2014); "Los usos de energía como factor de diferenciación social: un análisis en los ámbitos urbano y rural de México", en Graizbord, B. (ed.), Sustentabilidad metropolitana: estructura urbana, economía, ambiente y gestión pública, El Colegio de México, México, pp. 267-309 (2014); "Usos de energía eléctrica y mitigación del cambio climático en México: la necesidad de una nueva política pública”, en González, M. E., Gabriela Muńoz y Alfredo Ortega (eds.), Hacia la sustentabilidad ambiental de la producción de energía en México, El Colegio de la Frontera Norte (Colef), México, pp. 211-249 (2011); "Hacia una perspectiva de la sustentabilidad energética en México", en José Luis Lezama y Boris Graizbord (coords.), Medio Ambiente, vol. IV de Los grandes problemas de México, El Colegio de México, México, pp. 337-372 (2010).

Boris Graizbord. Doctor en geografía social por la London School of Economics and Political Science en Londres, Inglaterra. Maestro en geografía urbana de la Universidad de Durham, Inglaterra. Es profesorinvestigador del Centro de Estudios Demográficos, Urbanos y Ambientales de El Colegio de México. Pertenece al Sistema Nacional de Investigadores, nivel III. Ha sido coordinador del Programa de Estudios Avanzados en Desarrollo Sustentable y Medio Ambiente (LEAD-México) de El Colegio de México desde 1995. Fue coordinador académico del Programa de Estudios Urbanos de El Colegio de México en dos ocasiones (1984-1986 y 1994-1995). Ha sido invitado regularmente a dar cursos completos o cortos en otras instituciones académicas tanto del país como del extranjero (entre otras la University of Southern California, University of Pennsylvania y la New School University). Sus líneas de investigación son urbanización y medio ambiente, desastres naturales, dinámica de las ciudades medias, transporte metropolitano y desarrollo regional en México. Entre sus publicaciones destacan: "Geografía ambiental: disciplina híbrida fértil”, en C. Garrocho y G. Buzai (coords.), Geografía aplicada en Iberoamérica. Avances, retos y perspectivas, El Colegio Mexiquense, Zinacantepec, pp. 137-176 (2015); en coautoría: Ciudades sostenibles en México: una propuesta conceptual y operativa, Fondo de Población de las Naciones Unidas-Consejo Nacional de Población, México (2015); "Medio Ambiente, recursos y movilidad territorial en el México urbano", en La situación demográfica de México 2015, Conapo, México, pp. 229-248 (2015), "La migración como una opción de adaptación al cambio climático”, en M. Aragonés (coord.), Consecuencias del cambio climático sobre la migración: un análisis para México, Universidad Nacional Autónoma de México, México, pp. 61-80 (2015); 
Hacia una cultura de las ciudades sostenibles, Fondo de Población de las Naciones Unidas-Consejo Nacional de Población, México, (2014); "Desigualdades regionales, acceso al agua y cambio climático", Coyuntura Demográfica. Revista sobre los procesos demográficos en México hoy, núm. 4, Universidad Nacional Autónoma de México, México, pp. 87-94 (2013). 